\title{
A novel approach of developing micro crystalline cellulose reinforced cementitious composites with enhanced microstructure and mechanical performance
}

\author{
Shama Parveen ${ }^{a, *}$, Sohel Rana a , Raul Fangueiro ${ }^{a}$, Maria Conceição Paiva ${ }^{b}$ \\ ${ }^{a}$ Fibrous Materials Research Group (FMRG), School of Engineering, University of Minho, Campus de Azurém, 4800-058 Guimarães, Portugal \\ ${ }^{\mathrm{b}}$ Institute for Polymers and Composites (IPC), University of Minho, Campus de Azurém, 4800-058 Guimarães, Portugal
}

\section{A R T I C L E I N F O}

\section{Article history:}

Received 17 February 2016

Received in revised form

23 October 2016

Accepted 19 January 2017

Available online 25 January 2017

\section{Keywords:}

Microcrystalline cellulose (MCC)

Pluronic F-127

Dispersion

Cementitious matrix

Microstructure

Mechanical performance

\begin{abstract}
A B S T R A C T
This paper reports a novel approach of preparing aqueous suspensions of microcrystalline cellulose (MCC) for fabrication of cementitious composites. MCC was dispersed homogeneously in water using Pluronic F-127 as a surfactant with the help of ultrasonication process and the aqueous suspensions were added to cement/sand mixture to prepare cementitious composites. A commonly used stabilizing agent for MCC, carboxy methyl cellulose (CMC) was also used for the comparison purpose. The prepared suspensions were characterized through visual inspection, UV-Vis spectroscopy and optical microscopy. The developed composites were characterized for their bulk density, flexural and compressive properties as well as microstructure. The influence of Pluronic and CMC concentration, superplasticizer, dispersion technique and dispersion temperature on mortar's mechanical performance was thoroughly studied to find out the optimum conditions. Overall, Pluronic (with Pluronic: MCC ratio of 1:5) led to better MCC dispersion as well as dispersion stability as compared to CMC. The best mechanical performance was achieved with Pluronic in combination with superplasticizer using ultrasonication process, resulting in improvement of $106 \%, 31 \%$ and $66 \%$ in flexural modulus, flexural strength and compressive strengths, respectively (highest values reported till date). The bulk density and hydration of cementitious composites also improved significantly with the addition of MCC.
\end{abstract}

๑) 2017 Elsevier Ltd. All rights reserved.

\section{Introduction}

Cementitious materials are extensively used in construction applications. However, one inherent problem of cementitious materials is their brittleness and proneness towards crack formation. By virtue, they are composite materials consists of many constituents such as calcium silicate hydrate (C-S-H), calcium hydroxide, ettringite, monosulfate, unhydrated particles, etc. which are formed when cement reacts with water [1]. Cracks are formed within cementitious composites during manufacturing or service and propagate with time, eventually leading to failure. Environmental conditions also aggravate the cracking phenomena in cementitious materials. Frequently, cementitious materials are reinforced with different fibres such as glass, carbon, aramid, basalt,

\footnotetext{
* Corresponding author.

E-mail address: parveenshama2011@gmail.com (S. Parveen).
}

steel, etc. to improve their strength and ductility [2]. Also, the use of different nanomaterials such as nano $\mathrm{TiO}_{2}$, nano clay, nano $\mathrm{SiO}_{2}$, carbon nanotube (CNT), carbon nano fibre (CNF), etc. have been extensively studied to enhance various properties of cement including mechanical strength, stiffness, fracture toughness, electrical conductivity, self-sensing, self-cleaning, and so on [3-6]. Nanomaterials are advantageous as they can arrest the growth of cracks at nanoscale, resulting in strong improvement in fracture performance of cementitious materials.

Recently, there is a growing interest on different bio-based technical fibres such as flax, jute, hemp, sisal, etc. for reinforcing polymeric as well as cementitious composites due to concern about environment and sustainability. Due to the same reason, the use of natural nano and micro reinforcements such as nano cellulose (e.g. nano fibrillar cellulose or NFC, nano crystalline cellulose or NCC and bacterial nano cellulose or BNC) and microcrystalline cellulose (MCC) are getting considerable attention in different industrial applications [7-9]. MCC is crystalline structure of cellulose with 
diameter and length of more than $1 \mu \mathrm{m}$ and aspect ratio of about 1 . MCC is derived from cellulose by acid hydrolysis followed by homogenization and is commercially available [6-9]. MCC possesses excellent mechanical properties (axial elastic modulus 120-200 GPa, tensile strength 7.5 GPa) and already finds applications in food, cosmetics, medical and hygiene products, emulsions, etc [7-9]. Both nano cellulose and MCC have been extensively used as reinforcements of polymeric matrices [10-14]. However, they have been rarely studied as reinforcements of cementitious composites for construction applications. Very recently, well dispersed nano cellulose (as received from the acid hydrolysis) was found to improve the flexural strength of cement by $30 \%$ [15]. BNC has also been used as fibre coating in bagasse fibre reinforced cement composites resulting in stronger fibre/cement interface and reduced fibre mineralization [16]. Similarly, MCC was also used for reinforcement of cementitious materials; however, no improvement in mechanical performance was achieved [17]. In this work, MCC was saturated with water and mixed with cement without any dispersion step. So, non-homogeneous dispersion of MCC could be the main reason behind its ineffectiveness in enhancing mechanical performance. Similar to other nano and micro materials, dispersion of MCC is also believed to be highly important with respect to the mechanical properties, as MCC agglomeration can significantly reduce its reinforcing efficiency and leads to defects within cementitious materials. Therefore, to ensure homogeneous dispersion of MCC within cementitious matrix, the present study reported the first attempt of using a surfactant (Pluronic F-127) to fabricate MCC reinforced cementitious composites.

Surfactants have been extensively used to disperse CNTs in polymers and cement [18-21]. Similarly, cellulose nanofibres and nano whiskers were also dispersed in various solvents and matrices using different cationic and non-ionic surfactants such as hexadecyltrimethylammonium (HDTMA), cetyltrimethylammonium bromide (CTAB), didecyldimethylammonium bromide (DMAB), sorbitan monostearate, etc. [8]. Besides non-covalent approaches, the use of covalent functionalization such as acetylation and esterification, cationisation, silylation, 2,2,6,6tetramethylpiperidine-1-oxyl (TEMPO) mediated oxidation and functionalization, polymer grafting, etc. have also been tried to improve dispersion of cellulose nano whiskers [8]. Among various surfactants, Pluronic F-127 is a biocompatible surfactant which has been widely used for dispersing CNTs [22,23]. Recently, Pluronic F127 has been used by the authors to homogeneously disperse CNTs within cementitious composites [24]. In addition to superior ability of Pluronic F-127 to disperse CNTs, this study also revealed the possibility of obtaining better microstructure of cementitious composites using Pluronic [24]. This was attributed to the fact that Pluronic can work as a superplasticizer due to the polyethylene oxide (PEO) chains. Based on this positive finding, Pluronic F-127 has been used in the present work to prepare aqueous MCC suspensions for fabricating cementitious composites. Additionally, carboxy methyl cellulose (CMC), which is frequently used as stabilizing agent for MCC in industrial applications [25], has been used in order to compare its performance with Pluronic F-127. The effect of different conditions (e.g. use of superplasticizer, higher water ratio, magnetic stirring/ultrasonication and high temperature) on flexural and compressive performance of cementitious composites was investigated to in order to find the optimum conditions to maximize mechanical performance.

\section{Experimental}

\subsection{Raw materials}

MCC (Avicel ${ }^{\circledR}$ PH-101) was purchased from Sigma Aldrich
(Portugal). The morphology of MCC, as characterized by Scanning Electron Microscopy (FEG-SEM, NOVA 200 Nano SEM, FEI, acceleration voltage: $10 \mathrm{kV}$, coating: $30 \mathrm{~nm}$ Au-Pd) is shown in Fig. 1. It can be observed that the cellulose microcrystals were highly agglomerated in the powder. X-ray diffraction (XRD, Bruker D8 Discover, angle range: $5-70^{\circ}$, step size: 0.04 , time per step: $2 \mathrm{~s}$ ) pattern of MCC is provided in Fig. 2, which indicates the presence of cellulose-I allomorph. The peaks obtained at $14.8,16.3$ and $22.4^{\circ} 2 \theta$ correspond to $11 \overline{0}, 110$ and 200 reflections, respectively. Pluronic F127 and CMC, which were used to disperse MCC in water, were also supplied by Sigma Aldrich (Portugal). The superplasticizer used for the fabrication of cementitious composites was MasterGlenium SKY 526, supplied by BASF. Table 1 lists the important properties of these materials. The details of cement and sand used for developing cementitious composites are listed in Table 2.

\subsection{Methods}

\subsubsection{Preparation of aqueous MCC suspensions}

The aqueous suspensions of MCC/Pluronic or CMC were prepared by first mixing MCC in water by the help of magnetic stirring for $10 \mathrm{~min}$. The aqueous MCC suspensions were then stored for 2 days for soaking and subsequently, the surfactant Pluronic F-127 or stabilizer $\mathrm{CMC}$ was added through magnetic stirring for $5 \mathrm{~min}$. The MCC suspensions were then kept in a bath ultrasonicator (CREST Ultrasonicator, CP 230T) operated at $45 \mathrm{kHz}$ frequency and $80 \mathrm{~W}$ power for $15 \mathrm{~min}$. For a few suspensions, ultrasonication was avoided and only magnetic stirring (MS) was used for $30 \mathrm{~min}$, instead of ultrasonication. Also, for some suspensions an additional MS step of $30 \mathrm{~min}$ at high temperature $\left({ }^{\circ} 60 \mathrm{C}\right)$ was used after ultrasonication. The objective behind using these dispersion conditions was to study their influence on the mechanical performance of cementitious composites. For the suspensions prepared using Pluronic, a defoamer, tri butyl phosphate ( $1 / 2$ of surfactant weight) was used to supress the formation of foam. For preparation of aqueous MCC suspensions, a CMC: MCC weight ratio of 1:5 has been used as recommended for commercial applications [25] and Pluronic was also used in the same ratio for comparison purpose.

\subsubsection{Characterization of aqueous MCC suspensions through UV-Vis spectroscopy}

MCC aqueous suspensions prepared with Pluronic and CMC using ultrasonication were characterized by UV-Vis spectroscopy (within $24 \mathrm{~h}$ of their preparation) to measure the concentration of MCC suspended in the solution. The suspensions showing lower absorption indicate lower MCC concentration in the solution due to lower stability and sedimentation. Suspensions prepared by varying MCC concentration (0.4-1.5 wt \%) were studied by UV-Vis spectroscopy, in order to study the stability of the suspensions at different MCC concentrations. For each measurement, same concentrations of Pluronic/CMC solution (without MCC) were used as blank to eliminate the peaks due to Pluronic/CMC. To measure the concentration of MCC in the suspensions, a calibration curve of absorbance vs. concentration was prepared. The calibration curve was prepared by measuring the absorbance of different MCC suspensions with known concentrations $(0.1 \%-0.4 \%)$. The UV absorption of MCC at $300 \mathrm{~nm}$ was measured to construct the calibration curve.

\subsubsection{Characterization of aqueous MCC suspensions through optical microscopy}

MCC suspensions prepared with Pluronic and CMC using ultrasonication were characterized for dispersion homogeneity and agglomerates using optical microscopy. For this purpose, a drop of the suspension was taken on glass slide and covered using a glass 


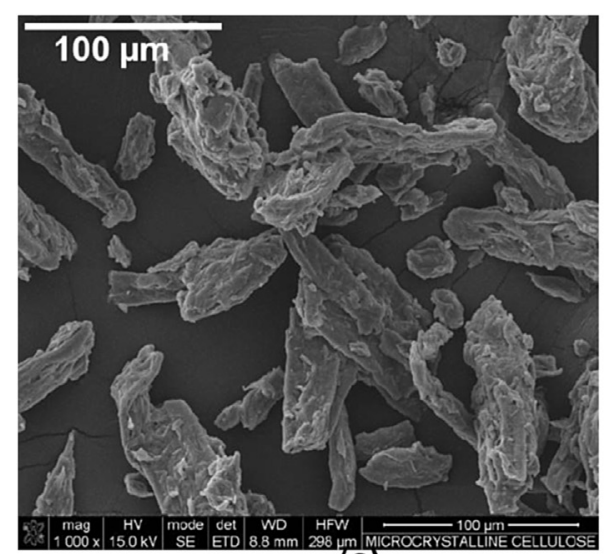

(a)

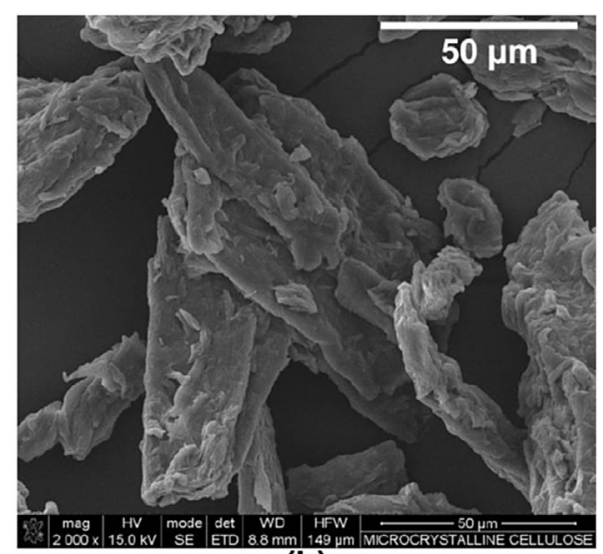

(b)

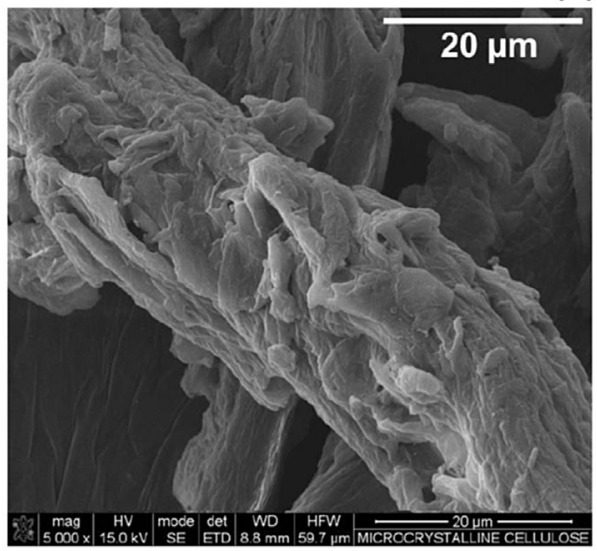

(c)

Fig. 1. Morphology of MCC, as characterized by SEM, at different magnifications.

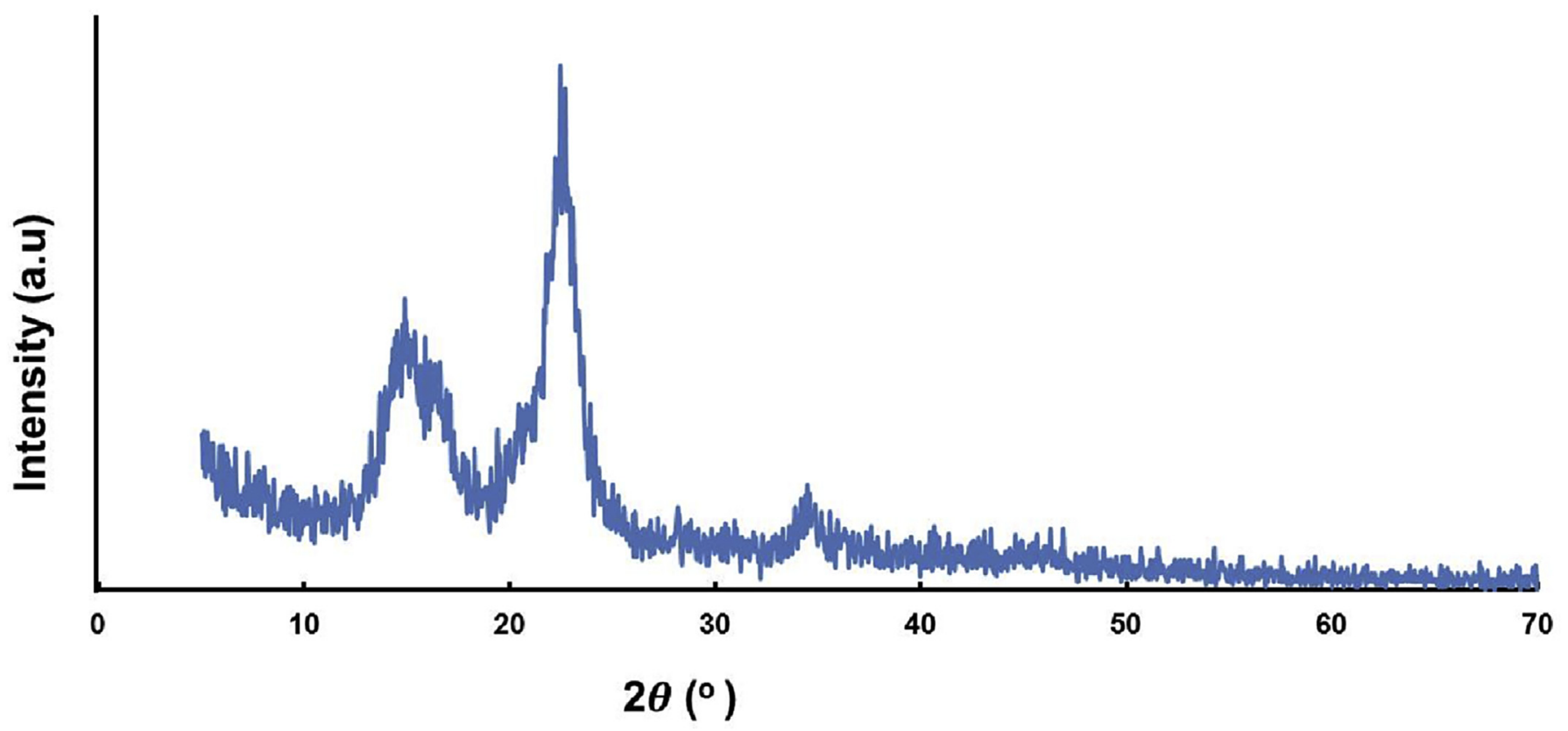

Fig. 2. XRD pattern of microcrystalline cellulose. 
Table 1

Properties of raw materials.

\begin{tabular}{ll}
\hline Materials & Properties \\
\hline MCC $^{\text {a }}$ & $\begin{array}{l}\text { Particle size range: } 2-260 \mu \mathrm{m} \text {, Sauter mean } \\
\text { diameter: } 49.1 \mu \mathrm{m}, \text { moisture content } \sim 3 \mathrm{wt} \%\end{array}$ \\
& $\begin{array}{l}\text { solid density: } 1.54 \mathrm{~g} / \mathrm{cm}^{3} \text {, Particle shape: larger } \\
\text { fibrous rods to smaller irregular cuboids } \\
\text { Average molecular weight: } 12,500, \text { non-ionic } \\
\text { surfactant, critical micelle conc.: } 950-1000 \mathrm{ppm}\end{array}$ \\
& $\begin{array}{l}\text { Average molecular weight: } 90,000, \text { stabilizer } \\
\text { Pluronic F-127 }\end{array}$ \\
$\mathrm{CMC}^{\mathrm{b}}$ & Superplasticizer, polycarboxylic ether type \\
MasterGlenium SKY 526 & \\
\hline a Source: Ref. [26]. & \\
b Source: Sigma Aldrich. &
\end{tabular}

slip and observed under optical microscope at different magnifications. Observations were made from different parts of each suspension prepared repeated times in order to get clear idea about the dispersion quality. The overall homogeneity, presence of individually dispersed MCC and agglomerated MCC were observed and compared for different suspensions. The optical characterization of the samples was performed within $24 \mathrm{~h}$ of the preparation.

\subsubsection{Fabrication of MCC/Cement composites}

Fabrication of MCC/cement composites was done by mixing the prepared MCC aqueous suspensions with Ordinary Portland Cement (OPC) and standardized sand using a standard mixer. The amounts of MCC added to the cement mixture were $0.25 \%, 0.75 \%$ and $1.5 \%$ (on the weight of cement mix) in case of Pluronic and $0.5 \%$, $1 \%$ and $1.5 \%$ in case of CMC. The cement: water ratio was always maintained at 0.5 except for one set of samples, for which the water: cement ratio was increased to 0.6 in order to study the effect of higher water ratio. The amount of superplasticizer was varied from 0 to $1.25 \mathrm{wt} \%$ for Pluronic samples and from 0 to $3 \mathrm{wt} \%$ for CMC samples.

Due to higher MCC conc., samples prepared with CMC needed higher superplasticizer to achieve required flow values of the mortar paste suitable for mixing, compacting and moulding. Both for CMC and Pluronic, higher amount of polycarboxylic ether superplasticizer was used for samples containing high MCC conc. to achieve the required flow values. The high water: cement ratio (0.6) was used only in case of CMC to avoid using high amount of superplasticizer. Also, ultrasonication was avoided and only MS was used for one set of samples prepared using Pluronic, in order to study whether MS will be sufficient to disperse relatively lower amount of MCC using Pluronic.

Prepared mortar mixes were characterized for flow or consistence (using a flow table according to EN 1015-3 standard), next poured in to rectangular moulds with dimensions of $160 \mathrm{~mm} \times 40 \mathrm{~mm} \times 40 \mathrm{~mm}$ and kept for $24 \mathrm{~h}$ in a humid atmosphere. Subsequently, the samples were demoulded and kept under water for hydration for 28 days. After 28 days, the samples were taken out from water, air dried at room temperature for $2 \mathrm{~h}$ to remove surface water (to avoid slippage during mechanical testing) and tested for dry bulk density and mechanical properties. Mechanical testing was carried out in standard laboratory conditions. One set of plain mortar samples without MCC and dispersant was also prepared as reference samples for comparison purpose. The details of sample prepared are provided in Tables 3 and 4, along with the flow values of prepared mortar mixes.

\subsubsection{Characterization of mechanical performance and dry bulk density}

Plain mortar and MCC/cement composites were characterized for flexural and compressive properties according to BS EN 1961:1995 standard. The fracture energy of the samples was calculated from the area under the flexural load-deflection curves. Also, plain mortar, mortar containing Pluronic and $\mathrm{CMC}$ and $\mathrm{MCC} /$ mortar samples were characterized for dry bulk density A according to BS EN 1015-10:1999 standard using the following equation:

$A=\frac{\text { Ms, dry }}{\text { Vs }}$

$\mathrm{Vs}=\frac{\mathrm{Ms}, \text { sat }-\mathrm{Ms}, \mathrm{i}}{\rho \mathrm{W}}$

Where $\mathrm{M}_{\mathrm{s}, \mathrm{dry}}$ is the oven dry mass of specimen of hardened mortar $(\mathrm{kg}), \mathrm{M}_{\mathrm{s}, \mathrm{sat}}$ is the mass of saturated specimen of hardened mortar $(\mathrm{kg}), \mathrm{M}_{\mathrm{s}, \mathrm{i}}$ is the apparent mass of saturated specimen of hardened mortar immersed in water $(\mathrm{kg}), \rho_{\mathrm{w}}$ is the density of water $\left(\mathrm{kg} / \mathrm{m}^{3}\right)$ and $\mathrm{V}_{\mathrm{s}}$ is the volume of specimen of hardened mortar $\left(\mathrm{m}^{3}\right)$.

\subsubsection{Thermo-gravimetric analysis of MCC/cement composites}

Plain mortar and mortar containing MCC were characterized using Thermogravimetric Analyzer (TGA, Perkin Elmer) in nitrogen atmosphere at heating rate of $10{ }^{\circ} \mathrm{C} / \mathrm{min}$ up to $900{ }^{\circ} \mathrm{C}$. Derivative

Table 2

Properties of cement and sand used for fabricating cementitious composites.

\begin{tabular}{|c|c|c|}
\hline Material & Composition & $\begin{array}{l}95-100 \% \text { Clinker }+0-5 \% \\
\text { minor additional components }\end{array}$ \\
\hline \multirow[t]{8}{*}{ Ordinary Portland Cement (CEM I 42.5 R) } & Loss on ignition & $<\% 5$ \\
\hline & Insoluble residue & $\leq \% 5$ \\
\hline & Sulphur trioxide $\left(\mathrm{SO}_{3}\right)$ & $\leq \% 4.0$ \\
\hline & Chloride $\left(\mathrm{Cl}^{-}\right)$ & $\leq \% 0.1$ \\
\hline & Initial setting time & $\geq 60 \mathrm{~min}$ \\
\hline & Soundness & $\leq 10 \mathrm{~mm}$ \\
\hline & 2 days compressive strength & $\geq 20.0 \mathrm{MPa}$ \\
\hline & 28 days compressive strength & $\geq 42.5 \mathrm{MPa} \leq 62.5 \mathrm{MPa}$ \\
\hline \multirow[t]{9}{*}{ Sand (NP-EN 196-1) } & Moisture content & $\leq \% 0.2 \%$ \\
\hline & Particle size distribution & \\
\hline & Square mesh size (mm) & Cumulative sieve residue (\%) \\
\hline & 2.00 & 0 \\
\hline & 1.60 & $7 \pm 5$ \\
\hline & 1.00 & $33 \pm 5$ \\
\hline & 0.50 & $67 \pm 5$ \\
\hline & 0.16 & $87 \pm 5$ \\
\hline & 0.08 & $99 \pm 1$ \\
\hline
\end{tabular}

\footnotetext{
a Source: www.secil.pt.

b www.tecnilab.pt.
} 
Table 3

Details of Samples Prepared using CMC.

\begin{tabular}{|c|c|c|c|c|c|c|}
\hline Samples & CMC:MCC & Super-plasticizer & Water Ratio & Dispersion Conditions & Sample Code & Flow Values \\
\hline Cement $+0.5 \% \mathrm{MCCC}+\mathrm{CMC}$ & $1: 5$ & No & 0.6 & Ultrasonication & $0.5 \mathrm{MC}+\mathrm{CMC}+0.6 \mathrm{~W}$ & 220,215 \\
\hline Cement $+1.0 \% \mathrm{MCCC}+\mathrm{CMC}$ & $1: 5$ & No & 0.6 & Ultrasonication & $1 \mathrm{MC}+\mathrm{CMC}+0.6 \mathrm{~W}$ & 170,170 \\
\hline Cement $+1.5 \% \mathrm{MCC}+\mathrm{CMC}$ & $1: 5$ & No & 0.6 & Ultrasonication & $1.5 \mathrm{MC}+\mathrm{CMC}+0.6 \mathrm{~W}$ & 90,94 \\
\hline Cement $+0.5 \% \mathrm{MCC}+\mathrm{CMC}$ & $1: 5$ & Yes & 0.5 & Ultrasonication & $0.5 \mathrm{MC}+\mathrm{CMC}+\mathrm{SP}$ & 180,180 \\
\hline Cement $+1.0 \% \mathrm{MCC}+\mathrm{CMC}$ & $1: 5$ & Yes & 0.5 & Ultrasonication & $1 \mathrm{MC}+\mathrm{CMC}+\mathrm{SP}$ & 156,158 \\
\hline Cement $+1.5 \% \mathrm{MCC}+\mathrm{CMC}$ & $1: 5$ & Yes & 0.5 & Ultrasonication & $1.5 \mathrm{MC}+\mathrm{CMC}+\mathrm{SP}$ & 170,170 \\
\hline Cement $+0.5 \% \mathrm{MCC}+\mathrm{CMC}$ & $1: 5$ & Yes & 0.5 & Ultrasonication, MS at $60{ }^{\circ} \mathrm{C}$ & $0.5 \mathrm{MC}+\mathrm{CMC}+\mathrm{SP}+\mathrm{T}$ & 210,210 \\
\hline Cement $+1.0 \% \mathrm{MCC}+\mathrm{CMC}$ & $1: 5$ & Yes & 0.5 & Ultrasonication, MS at $60{ }^{\circ} \mathrm{C}$ & $1 \mathrm{MC}+\mathrm{CMC}+\mathrm{SP}+\mathrm{T}$ & 150,155 \\
\hline Cement $+1.5 \% \mathrm{MCC}+\mathrm{CMC}$ & $1: 5$ & Yes & 0.5 & Ultrasonication, $\mathrm{MS}$ at $60^{\circ} \mathrm{C}$ & $1.5 \mathrm{MC}+\mathrm{CMC}+\mathrm{SP}+\mathrm{T}$ & 185,184 \\
\hline
\end{tabular}

Table 4

Details of Samples Prepared using Pluronic.

\begin{tabular}{|c|c|c|c|c|c|c|}
\hline Samples & Pluronic: MCC & Super-plasticizer & Water Ratio & Dispersion Conditions & Sample Code & Flow Values \\
\hline Cement $+0.25 \%$ MCC + Pluronic & $1: 5$ & Yes & 0.5 & MS & $0.25 \mathrm{MC}+\mathrm{P}+\mathrm{SP}+\mathrm{MS}$ & High \\
\hline Cement $+0.5 \%$ MCC + Pluronic & $1: 5$ & Yes & 0.5 & MS & $0.5 \mathrm{MC}+\mathrm{P}+\mathrm{SP}+\mathrm{MS}$ & High \\
\hline Cement $+0.75 \% \mathrm{MCC}+$ Pluronic & $1: 5$ & Yes & 0.5 & MS & $0.75 \mathrm{MC}+\mathrm{P}+\mathrm{SP}+\mathrm{MS}$ & 170,170 \\
\hline Cement $+0.25 \% \mathrm{MCC}+$ Pluronic & $1: 5$ & Yes & 0.5 & Ultrasonication & $0.25 \mathrm{MC}+\mathrm{P}+\mathrm{SP}$ & 200,200 \\
\hline Cement $+0.5 \%$ MCC + Pluronic & $1: 5$ & Yes & 0.5 & Ultrasonication & $0.5 \mathrm{MC}+\mathrm{P}+\mathrm{SP}$ & 170,170 \\
\hline Cement $+0.75 \% \mathrm{MCC}+$ Pluronic & $1: 5$ & Yes & 0.5 & Ultrasonication & $0.75 \mathrm{MC}+\mathrm{P}+\mathrm{SP}$ & 200,200 \\
\hline Cement $+0.25 \% \mathrm{MCC}+$ Pluronic & $1: 5$ & Yes & 0.5 & Ultrasonication, MS at $60{ }^{\circ} \mathrm{C}$ & $0.25 \mathrm{MC}+\mathrm{P}+\mathrm{SP}+\mathrm{T}$ & 185,184 \\
\hline Cement $+0.5 \%$ MCC + Pluronic & $1: 5$ & Yes & 0.5 & Ultrasonication, MS at $60{ }^{\circ} \mathrm{C}$ & $0.5 \mathrm{MC}+\mathrm{P}+\mathrm{SP}+\mathrm{T}$ & High \\
\hline Cement $+0.75 \%$ MCC + Pluronic & $1: 5$ & Yes & 0.5 & Ultrasonication, MS at $60{ }^{\circ} \mathrm{C}$ & $0.75 \mathrm{MC}+\mathrm{P}+\mathrm{SP}+\mathrm{T}$ & High \\
\hline
\end{tabular}

thermogravimetry (DTG) curves of these samples were analyzed for obtaining quantitative estimation of various hydration products such as $\mathrm{C}-\mathrm{S}-\mathrm{H}, \mathrm{Ca}(\mathrm{OH})_{2}$ and $\mathrm{CaCO}_{3}$. The influence of MCC on the hydration degree of cement was studied from this characterization.

\subsubsection{X-ray diffraction (XRD) analysis of MCC/cement composites}

XRD analysis of plain mortar and selected MCC/cement composites was carried out to characterize various hydration products. XRD analysis was carried out using Bruker D8 Discover diffractometer in the angle range of $5-70^{\circ}$ with step size of 0.04 and $2 \mathrm{~s}$ per step.

\subsubsection{Microstructural characterization of MCC/Cement composites}

Microstructure of $\mathrm{MCC} / \mathrm{cement}$ composites was characterized by investigating the fracture surface by SEM (FEG-SEM, NOVA 200 Nano SEM, FEI) using secondary electron mode and acceleration voltage of $10 \mathrm{kV}$ ) after coating with a thin film (30 nm) of Au-Pd in a high resolution sputter coater (208HR Cressington). Elemental analysis of mortar and MCC particles present in the fracture was performed with the help of Energy dispersive X-ray Spectroscopy (EDS using EDAX Si(Li) detector) with an acceleration voltage of $15 \mathrm{kV}$ Further, the pore size and distribution of plain mortar and selected $\mathrm{MCC} /$ mortar composites were analyzed using mercury intrusion porosimetry (MIP) instrument (Micromeritics AutoPore IV 9500 V1.07) using pressure range of 0.0007-414 MPa, which allowed measurement of pore size ranging from $340 \mu \mathrm{m}$ to $5 \mathrm{~nm}$. An advancing/receding contact angle of mercury of $30^{\circ}$ and surface tension of $0.485 \mathrm{~N} / \mathrm{m}$ were used in the analysis.

\section{Results and discussion}

\subsection{Aqueous dispersion of MCC: visual inspection}

Fig. 3 shows the state of aqueous MCC suspensions prepared with Pluronic and CMC using ultrasonication, as observed by visual inspection. Pluronic/CMC: MCC ratio of 1:5 has been used to prepare the aqueous suspensions.

It can be clearly observed that up to $0.6 \%$, the suspensions were clear without any sedimentation in case of Pluronic (Fig. 3a). However, for $0.8 \%$ or higher concentrations, sedimentation can be clearly noticed, as indicated by arrows. On the contrary, for suspensions prepared using CMC, sedimentation was observed in all concentrations (Fig. $3 \mathrm{~b}$ ). This indicates that at Pluronic: MCC ratio of $1: 5$, Pluronic could provide stable suspension up to $0.6 \%$ MCC and at higher concentrations, the stability of the suspensions was poor, similar to all CMC suspensions. Pluronic was found to be more effective in providing stable suspension as compared to CMC, as it is a non-ionic surfactant containing hydrophobic and hydrophilic segments of polypropylene oxide (PPO) and polyethylene oxide (PEO), among which PPO segments may be adsorbed on MCC while PEO segments extend into the water providing steric stabilization. However, at higher concentrations, MCC forms highly

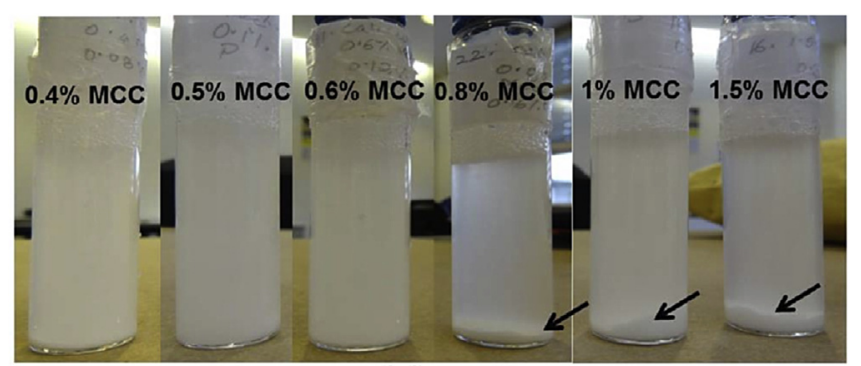

(a)

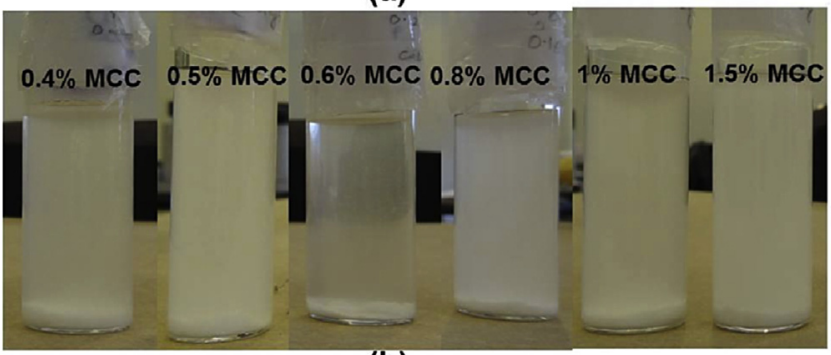

(b)

Fig. 3. Aqueous suspension of MCC with Pluronic (a) and CMC (b). 
agglomerated structures in contrast to the loose agglomerates formed at lower concentrations. Penetration of surfactant molecules into these dense agglomerates and their subsequent deagglomeration is much more difficult as compared to the loose MCC agglomerates. Moreover, the chances of re-agglomeration of dispersed MCC increase when MCC concentration is increased and consequently, higher surfactant ratio may be required to prevent MCC re-aggregation. Therefore, to facilitate the opening of MCC agglomerates formed at higher concentrations as well as to prevent re-aggregation of dispersed MCC, higher Pluronic ratio was tried, as shown in Fig. 4.

The high concentration suspensions prepared without Pluronic showed considerable sedimentation, similar to those prepared using 1\% Pluronic. However, 2\% MCC could be dispersed well without any sedimentation using $2 \%$ Pluronic, i.e. using a Pluronic: MCC ratio of $1: 1$, as indicated by arrow in Fig. 4c. Nonetheless, $4 \%$ and $6 \%$ Pluronic could not be dispersed well using $2 \%$ Pluronic. Increasing Pluronic concentration further may provide stable dispersion of these concentrated suspensions; however, this has been avoided in this research as too much use of Pluronic can have adverse effects (for example, can excessively increase flow values of cement mortar) on the performance of mortar paste.

\subsection{Characterization of MCC dispersion quality using UV-Vis spectroscopy}

UV-Vis spectra of MCC suspensions are provided in Fig. 5. The concentrations of MCC in the suspensions, as calculated using the calibration curve (Fig. s1, supplementary information), are provided in Table 5. For Pluronic, higher absorption was obtained up to $0.8 \%$ MCC, indicating that higher amount of MCC (up to $0.37 \%$ ) was present in the suspensions in well dispersed condition. At higher MCC conc., i.e. 1.5\% absorption reduced significantly. This was attributed to sedimentation of large amount of MCC leading to significant decrease in the MCC concentration (only $0.12 \%$ ) in the suspension. This observation is in well agreement with the visual inspection of sedimentation, as discussed in section 3.1.

In case of CMC, however, similar absorption was noticed for MCC concentrations ranging from 0.4 to $0.6 \%$. Higher absorption was obtained in case of higher MCC concentrations, i.e. $0.8 \%$ and $1.5 \%$, indicating higher amount of dispersed MCC $(0.38 \%$ and $0.35 \%$, respectively) in the suspensions. It can be noticed that much higher concentration $(0.35 \%)$ of MCC could be dispersed using CMC for $1.5 \%$ MCC as compared to Pluronic (only $0.12 \%$ ). Better performance of CMC at higher MCC concentration could be due to larger molecules of CMC (higher molecular weight), which prevent MCC reaggregation and sedimentation. As chances of MCC reaggregation are more at higher concentration, the use of CMC was found highly helpful for higher MCC concentrations. However, at lower concentrations, due to relatively smaller molecular structure of Pluronic, its penetration into MCC agglomerates and subsequent de-agglomeration and stabilization could be better than CMC. Based on these observations, higher amount of MCC has been dispersed using CMC as compared to Pluronic for fabricating cementitious composites.

\subsection{Characterization of dispersion quality through optical microscopy}

The state of MCC dispersion using Pluronic (using Pluronic: MCC ratio of 1:5) can be observed from the optical micrographs presented in Fig. 6 . It can be noticed that at $0.5 \%$ conc., cellulose crystals were homogeneously dispersed and many individually dispersed crystals can be observed in the suspension. This can be clearly observed at high magnification (Fig. 6a). At 1\% also, significant number of individual MCC could be observed along with agglomerated crystals. At $1.5 \%$, however, most of the cellulose micro crystals were highly agglomerated. The dispersion quality was

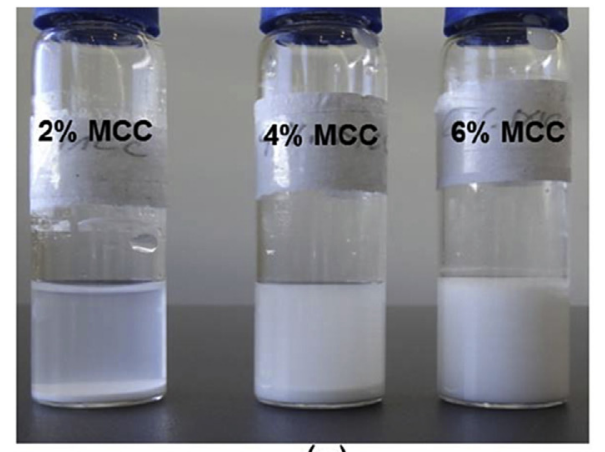

(a)

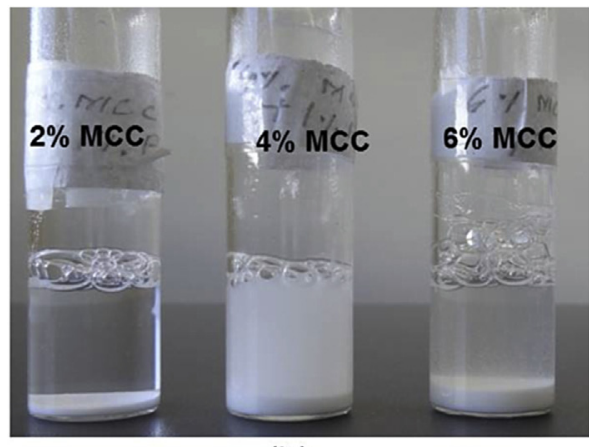

(b)

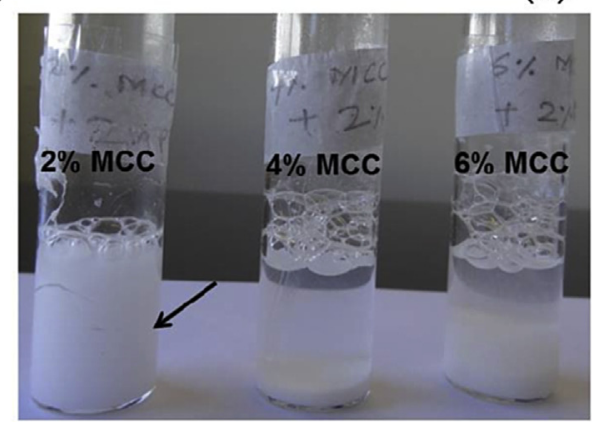

(c)

Fig. 4. MCC suspensions prepared using Pluronic: (a) $0 \%$ Pluronic and (b) $1 \%$ Pluronic and (c) $2 \%$ Pluronic. 

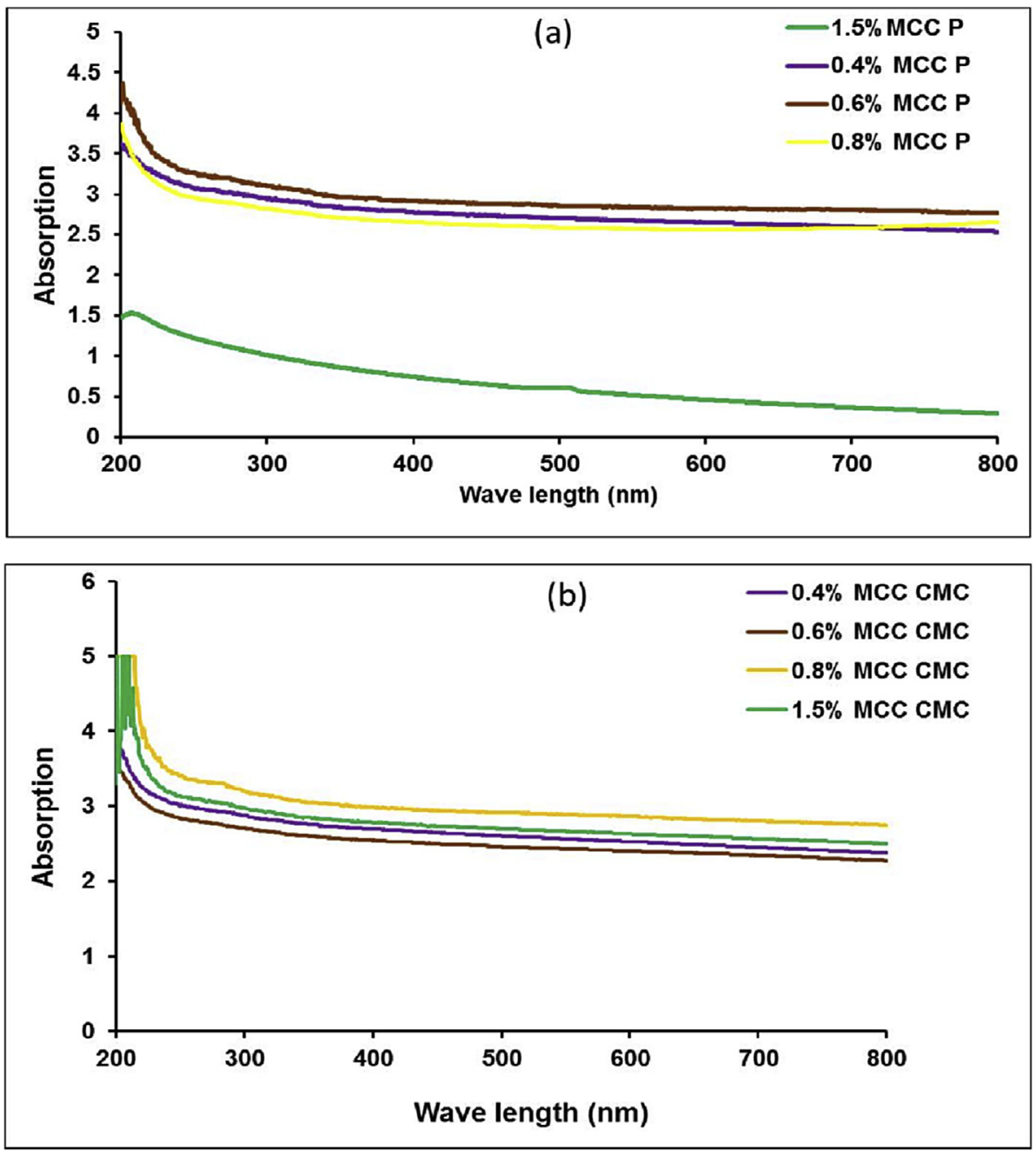

Fig. 5. UV-Vis absorption spectra for (a) Pluronic and (b) CMC suspensions [MCC: micro crystalline cellulose, CMC: carboxymethyl cellulose, P: pluronic].

inferior in case of CMC with respect to Pluronic mainly at low MCC concentrations, as can be observed from optical micrographs provided in Fig. 7. Even at 0.5\%, numerous MCC agglomerates were observed. Further, the suspensions containing $1 \%$ and $1.5 \%$ MCC exhibited highly agglomerated crystals of cellulose.

\subsection{Dry bulk density of cement and MCC/Cement composites}

Dry bulk density of plain cement mortar and mortar containing Pluronic and CMC, with or without MCC is listed in Table 6. It can be

Table 5

Concentration of MCC in aqueous suspensions, as determined by UV-Vis spectroscopy

\begin{tabular}{ll}
\hline Samples $^{\text {a }}$ & $\begin{array}{l}\text { Concentration in } \\
\text { aqueous suspension (\%) }\end{array}$ \\
\hline $0.4 \%$ MCC P & $0.35 \pm 0.004$ \\
$0.6 \%$ MCC P & $0.37 \pm 0.002$ \\
$0.8 \%$ MCC P & $0.34 \pm 0.003$ \\
$1.5 \%$ MCC P & $0.12 \pm 0.007$ \\
$0.4 \%$ MCC CMC & $0.34 \pm 0.002$ \\
$0.6 \%$ MCC CMC & $0.32 \pm 0.002$ \\
$0.8 \%$ MCC CMC & $0.38 \pm 0.005$ \\
$1.5 \%$ MCC CMC & $0.35 \pm 0.003$ \\
\hline
\end{tabular}

a MCC: micro crystalline cellulose, CMC: carboxymethyl cellulose, P: pluronic. observed that bulk density improved significantly with the addition of both Pluronic and CMC. Previous findings by the authors suggested that the presence of PEO side chains in Pluronic led to better dispersion of cement particles resulting in reduced porosity and improved mortar's bulk density [24]. Similarly, CMC contains carboxymethyl groups, which probably led to better dispersion of cement through steric stabilization mechanism, as also observed in case of polycarboxylate superplasticizers. As a result, bulk density of mortar containing CMC increased significantly. Addition of MCC also improved bulk density of mortar, similar to CMC or Pluronic, due to the same reason, i.e. steric stabilization of cement particles resulting in better dispersion. This type of mechanism has been already proposed for nano crystalline cellulose (NCC) [15] and is believed to be true for MCC as well as both of them have the same chemical structure. However, improvement of bulk density was not observed when MCC was dispersed using CMC (compare the bulk density of 3rd and 4th sample in Table 6) due to inferior MCC dispersion and increased porosity due to presence of MCC agglomerates.

\subsection{Mechanical properties of MCC/Cement composites}

The flexural stress-strain curves of plain mortar and MCC/ mortar samples are presented in Fig. 8. It can be observed that MCC addition to plain mortar has strongly improved its elastic modulus. 


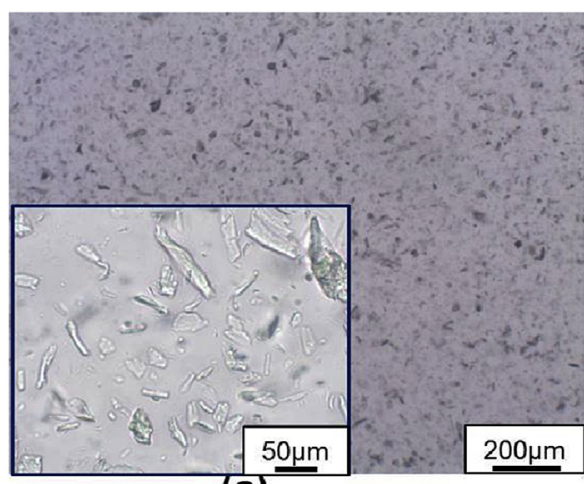

(a)

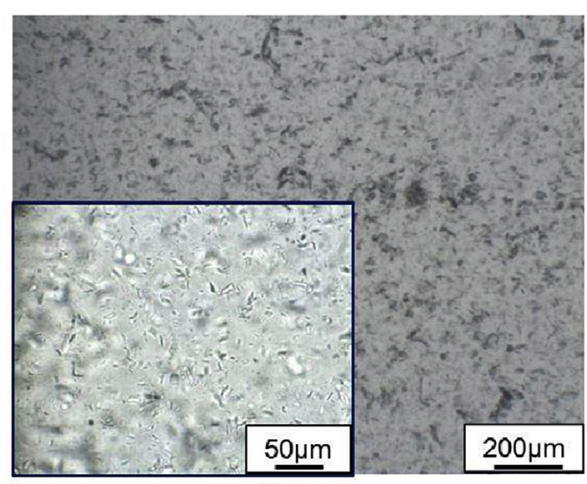

(b)

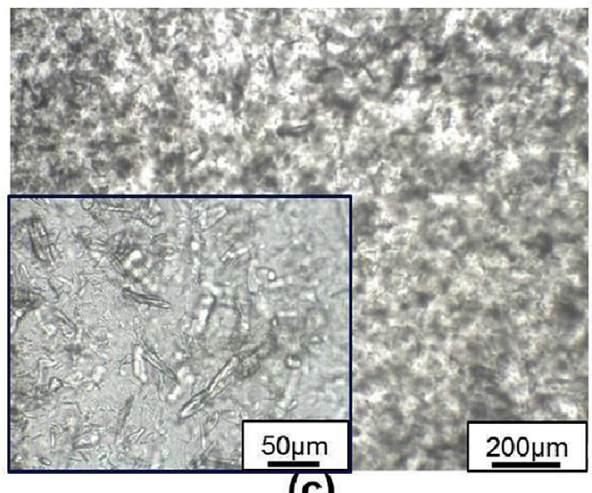

(c)

Fig. 6. Optical micrographs of MCC suspensions prepared using Pluronic: (a) $0.5 \%$ MCC, (b) $1 \%$ MCC, and (c) $1.5 \%$ MCC

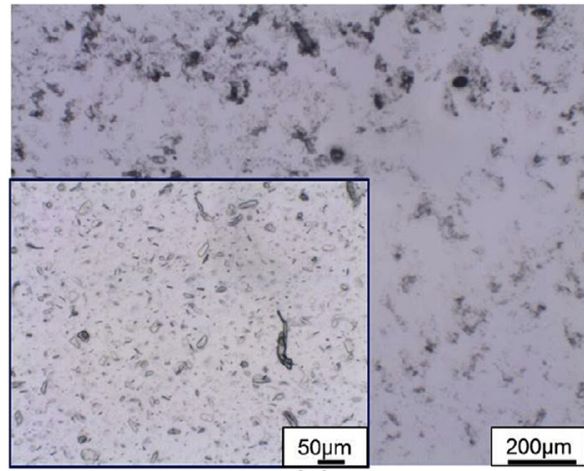

(a)

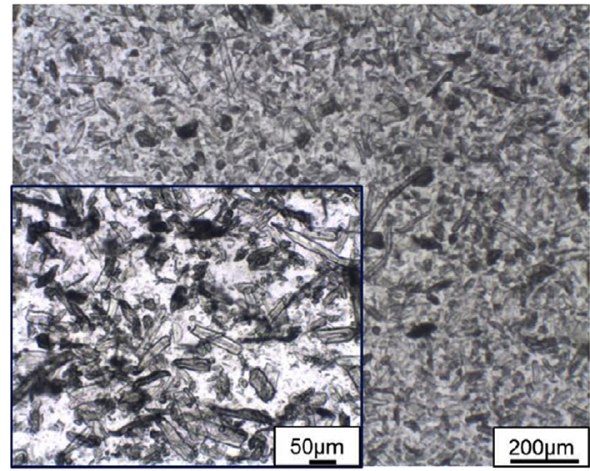

(b)

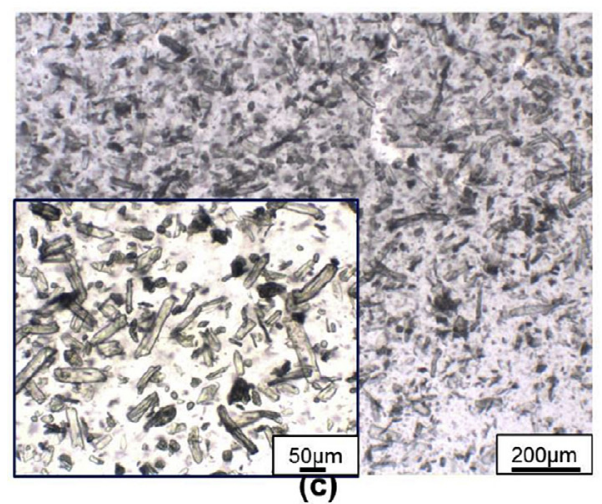

Fig. 7. Optical micrographs of MCC suspensions prepared using CMC: (a) $0.5 \%$ MCC, (b) $1 \%$ MCC and (c) $1.5 \%$ MCC. 
Table 6

Bulk density of plain mortar and MCC/mortar composites.

\begin{tabular}{ll}
\hline Samples $^{\text {a }}$ & Dry Bulk Density $\left(\mathrm{Kg} / \mathrm{m}^{3}\right)$ \\
\hline Plain cement mortar & 2012.4 \\
Mortar $+0.1 \% \mathrm{P}$ & 2020.8 \\
Mortar $+0.1 \%$ CMC & 2189.4 \\
Mortar $+0.5 \%$ MCC $+0.1 \%$ CMC & 2178.4 \\
Mortar $+0.5 \%$ MCC $+0.1 \% \mathrm{P}$ & 2158.5 \\
\hline
\end{tabular}

${ }^{\text {a }}$ MCC: micro crystalline cellulose, CMC: carboxymethyl cellulose, P: Pluronic.

Flexural strength has also improved significantly for most of the samples. Maximum improvements of $106 \%$ and $103.3 \%$ in flexural modulus were achieved through addition of $0.5 \%$ MCC using CMC and Pluronic, respectively, as listed in Table 7. Such a strong enhancement in flexural modulus was possible, due to high modulus of MCC and uniform dispersion of $0.5 \%$ MCC using Pluronic and $\mathrm{CMC}$.

However, as can be noticed in Table 7, fracture energy of mortar reduced significantly through addition of MCC. This could be due to the stiffening effect of MCC due to its high crystallinity and strong interface with the cementitious matrix, leading to reduced breaking strain of the matrix. This fact has also been observed previously in case polymer composites reinforced with MCC [27]. Moreover, MCC could not improve the fracture energy of cementitious matrix like other reinforcing materials with high aspect ratio such as carbon nanotubes (CNTs), probably due to its low aspect ratio and inability to bridge the cracks. Flexural strength, however, increased significantly for most of the samples, as can be observed from Fig. 9. Improvement of $31 \%$ in mortar's flexural strength was achieved with $0.5 \%$ MCC addition using Pluronic. Similarly, compressive strength of mortar also improved strongly with MCC addition in most of the cases (Fig. 10) and a maximum improvement of $66 \%$ in compressive strength was achieved through $0.5 \%$ MCC addition using Pluronic.

\subsubsection{Influence of processing parameters on mechanical properties}

The influence of processing parameters such as addition of superplasticizer, water ratio, ultrasonication/magnetic stirring, dispersion temperature as well as MCC concentration on flexural and compressive strengths can be understood from Figs. 9 and 10. It is clear that except the samples prepared using Pluronic and superplasticizer (with or without temperature), prepared cementitious composites showed decreased flexural and compressive strengths at high MCC concentrations. This was attributed to increased agglomeration of MCC at high concentrations, as observed from optical micrographs and UV-Vis spectroscopy results. The exception to this was observed for the samples in which dispersion was carried out using Pluronic and superplasticizer with or without higher temperature. In these cases, high conc. MCC could be dispersed well due to superplasticizer and high temperature and consequently, flexural (improved up to $0.75 \%$ MCC when dispersed without temperature and then decreased) and compressive strengths improved with MCC concentration.

Also, overall better flexural and compressive strengths were obtained using Pluronic (even at lower MCC concentrations) as compared to CMC, mainly owing to better MCC dispersion achieved in case of Pluronic than CMC. The highest flexural strength and compressive strengths were achieved with Pluronic and superplasticizer combination using the ultrasonication process. The use of magnetic stirring, instead of ultrasonication, resulted in lower mechanical performance due to its lower dispersion ability as compared to ultrasonication. The addition of mechanical stirring step at high temperature also reduced the mechanical performance. This was due to the fact that MCC retained significant amount of water during high temperature stirring, reducing available water required for proper mixing with cement and sand during preparation $\mathrm{MCC} / \mathrm{cement}$ composites. Therefore, improper mixing and compaction of cement paste increased the mortar's porosity and reduced the mechanical performance. In case of CMC also, the use of superplasticizer and ultrasonication process resulted in better mechanical properties. The use of higher water ratio, instead of using superplasticizer, was not found helpful, due to absence of positive effects of superplasticizer, i.e. dispersion of cement particles and also owing to increased porosity due to high water content in cement. Similar to Pluronic, the use of mechanical stirring at high temperature was not found to be beneficial for CMC also.

\subsection{Influence of MCC on cement hydration}

The weight loss and derivative weight loss curves of pure cement mortar and mortar containing $0.75 \%$ MCC (dispersed using Pluronic), obtained from TGA analysis, are presented in Fig. 11. The first peak 'a' near $100{ }^{\circ} \mathrm{C}$ represents the evaporation of free water and water present on the C-S-H surface [17]. The second peak ' $b$ ' is associated with the decomposition of $\mathrm{Ca}(\mathrm{OH})_{2}$. The third peak ' $\mathrm{c}$ ' represents the amount of $\mathrm{CaCO}_{3}$ present in all samples. However, peak ' $c$ ' is not a reliable measure for $\mathrm{CaCO}_{3}$, as its formation is also dependant on storage conditions (mainly the availability of atmospheric $\mathrm{CO}_{2}$ ) and overlapping peaks from mass loss of structural $\mathrm{OH}$ groups of C-S-H gel. It can be clearly observed that the intensity of the peaks ' $a$ ' and ' $b$ ' was much higher in case of mortar containing MCC. It implies that the formation of C-S-H gel and $\mathrm{Ca}(\mathrm{OH})_{2}$ was significantly higher in case of MCC reinforced cement samples due to higher degree of hydration. This finding is in well agreement with the previous studies [17]. Owing to higher water retention capacity, MCC can release and supply water as the hydration proceeds, leading to higher degree of hydration. The enhanced mechanical performance of mortar due to MCC addition could, therefore, be due to increased degree of cement hydration, besides the reinforcing effect of MCC.

The XRD patterns of the cement mortar and 0.75\% MCC reinforced mortar (with Pluronic) samples are provided in Fig. 12. In both samples, the peaks in XRD patterns confirm the presence of expected hydration products, including $\mathrm{Ca}(\mathrm{OH})_{2}$, ettringite, unreacted clinker phases (mainly calcium silicate phases, i.e. $\mathrm{C}_{2} \mathrm{~S}$ and $\mathrm{C}_{3} S$ ) [28]. However, C-S-H products did not show clear diffraction peaks, due to their semi-amorphous nature. The presence of $\mathrm{CaCO}_{3}$ was due to the partial carbonation of $\mathrm{Ca}(\mathrm{OH})_{2}$. It can be observed that $0.75 \%$ MCC reinforced cement mortar showed more sharp peaks of $\mathrm{Ca}(\mathrm{OH})_{2}$ as compared to plain cement mortar, indicating higher formation of $\mathrm{Ca}(\mathrm{OH})_{2}$, as also observed in TGA analysis. Also, plain mortar samples showed sharper peaks for anhydrous clinker phases, i.e. $\mathrm{C}_{2} \mathrm{~S}$ and $\mathrm{C}_{3} \mathrm{~S}$ as compared to $\mathrm{MCC} /$ cement samples, indicating presence of higher amount of unreacted products in plain mortar samples. Therefore, similar to TGA analysis, XRD also indicates better hydration in case of MCC reinforced cementitious composites.

\subsection{Microstructure of MCC/Cement composites}

Fracture surface of $\mathrm{MCC} / \mathrm{cement}$ composites is presented in Fig. 13. It can be clearly observed that MCC was well embedded within the structure of cement, as indicated by arrows. The results of EDS analysis on the plain mortar sample and the sample containing MCC on the locations indicated by arrows are provided in Table 8 and presented in supplementary material (Fig. 2S).

The relative increase in the C wt.\% and decrease in Ca and Si wt.\% proves the presence of cellulose crystals in $\mathrm{MCC} / \mathrm{cement}$ 

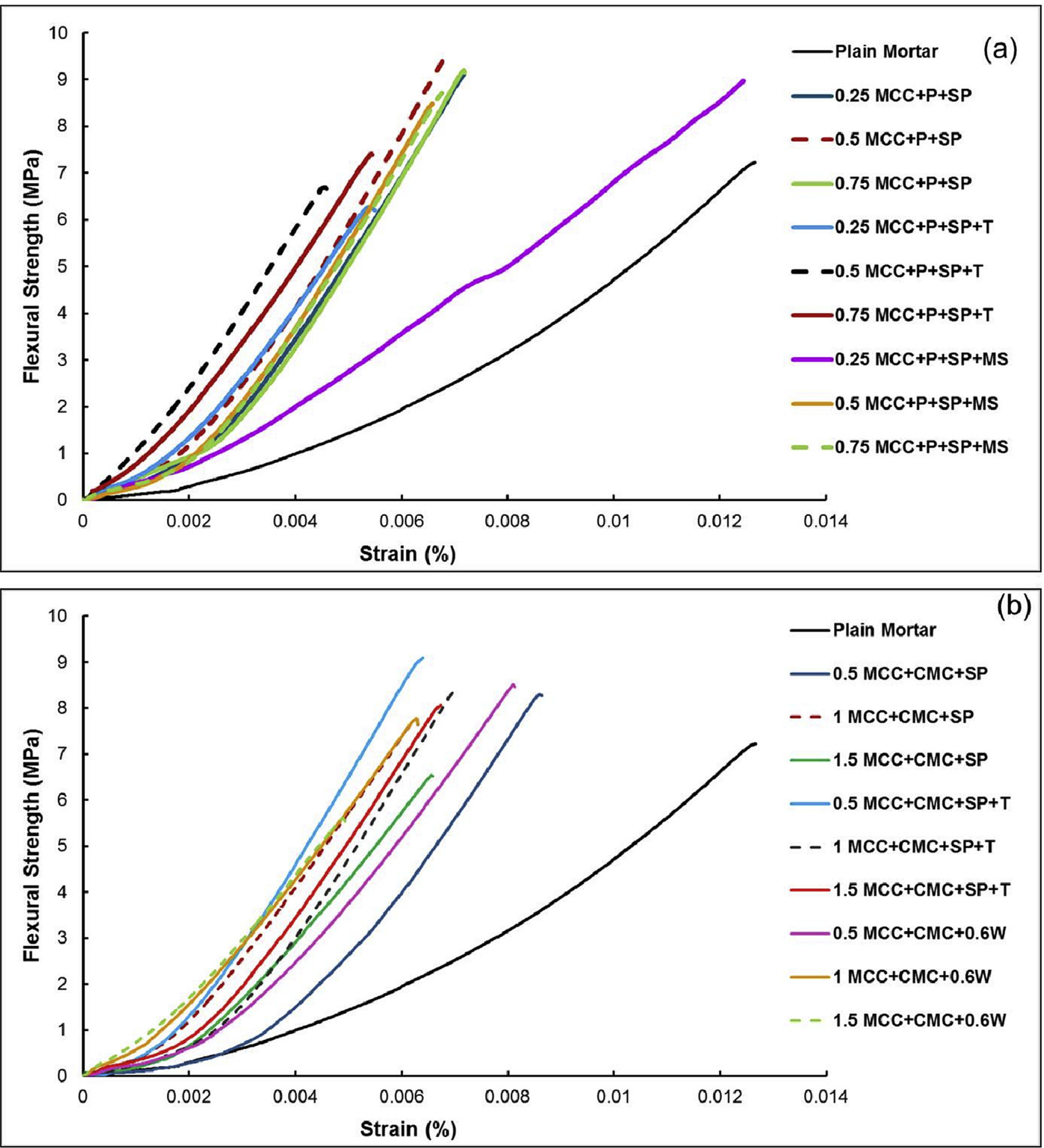

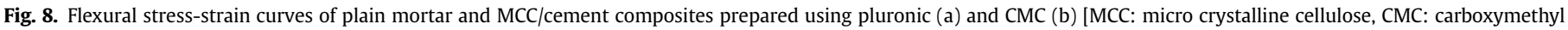
cellulose, SP: superplasticizer, T: temperature, W: water: cement ratio, P: pluronic, MS: mechanical stirring]. 
Table 7

Flexural modulus and fracture energy of plain cement mortar and $\mathrm{MCC} /$ cement composites.

\begin{tabular}{|c|c|c|c|c|}
\hline Samples ${ }^{\mathrm{a}}$ & Elastic modulus (GPa) & Modulus improvement (\%) & Maximum strain (\%) & Fracture energy (N.mm) \\
\hline Plain Mortar & $15.0 \pm 0.7$ & - & $0.013 \pm 0.0002$ & $804.3 \pm 5.0$ \\
\hline $0.5 \mathrm{MCC}+\mathrm{CMC}+\mathrm{SP}$ & $27.7 \pm 0.4$ & 84.7 & $0.009 \pm 0.0003$ & $408.6 \pm 4.6$ \\
\hline $1 \mathrm{MCC}+\mathrm{CMC}+\mathrm{SP}$ & $25.8 \pm 0.5$ & 72.0 & $0.006 \pm 0.0001$ & $347.0 \pm 8.1$ \\
\hline $1.5 \mathrm{MCC}+\mathrm{CMC}+\mathrm{SP}$ & $22.8 \pm 0.7$ & 52.0 & $0.007 \pm 0.0002$ & $289.9 \pm 10.4$ \\
\hline $0.5 \mathrm{MCC}+\mathrm{CMC}+\mathrm{SP}+\mathrm{T}$ & $30.9 \pm 0.2$ & 106.0 & $0.006 \pm 0.0002$ & $421.3 \pm 6.0$ \\
\hline $1 \mathrm{MCC}+\mathrm{CMC}+\mathrm{SP}+\mathrm{T}$ & $29.9 \pm 0.2$ & 99.3 & $0.007 \pm 0.0003$ & $373.6 \pm 8.8$ \\
\hline $1.5 \mathrm{MCC}+\mathrm{CMC}+\mathrm{SP}+\mathrm{T}$ & $27.6 \pm 0.4$ & 84.0 & $0.007 \pm 0.0002$ & $365.2 \pm 7.6$ \\
\hline $0.5 \mathrm{MCC}+\mathrm{CMC}+0.6 \mathrm{~W}$ & $25.2 \pm 0.5$ & 68.0 & $0.008 \pm 0.0001$ & $454.2 \pm 2.4$ \\
\hline $1 \mathrm{MCC}+\mathrm{CMC}+0.6 \mathrm{~W}$ & $24.2 \pm 0.6$ & 61.3 & $0.006 \pm 0.0003$ & $373.0 \pm 6.6$ \\
\hline $1.5 \mathrm{MCC}+\mathrm{CMC}+0.6 \mathrm{~W}$ & $25.2 \pm 0.8$ & 68.0 & $0.005 \pm 0.0004$ & $217.9 \pm 10.1$ \\
\hline $0.25 \mathrm{MCC}+\mathrm{P}+\mathrm{SP}$ & $29.0 \pm 0.3$ & 93.3 & $0.007 \pm 0.0003$ & $438.3 \pm 7.4$ \\
\hline $0.5 \mathrm{MCC}+\mathrm{P}+\mathrm{SP}$ & $30.3 \pm 0.3$ & 102.0 & $0.007 \pm 0.0002$ & $449.7 \pm 5.2$ \\
\hline $0.75 \mathrm{MCC}+\mathrm{P}+\mathrm{SP}$ & $27.7 \pm 0.2$ & 84.7 & $0.007 \pm 0.0002$ & $432.1 \pm 4.8$ \\
\hline $0.25 \mathrm{MCC}+\mathrm{P}+\mathrm{SP}+\mathrm{T}$ & $25.6 \pm 0.5$ & 70.7 & $0.005 \pm 0.0003$ & $243.8 \pm 4.4$ \\
\hline $0.5 \mathrm{MCC}+\mathrm{P}+\mathrm{SP}+\mathrm{T}$ & $27.3 \pm 0.6$ & 82.0 & $0.004 \pm 0.0005$ & $248.5 \pm 6.1$ \\
\hline $0.75 \mathrm{MCC}+\mathrm{P}+\mathrm{SP}+\mathrm{T}$ & $26.9 \pm 0.5$ & 79.3 & $0.005 \pm 0.0004$ & $317.3 \pm 9.2$ \\
\hline $0.25 \mathrm{MCC}+\mathrm{P}+\mathrm{SP}+\mathrm{MS}$ & $14.5 \pm 0.8$ & -3.3 & $0.012 \pm 0.001$ & $861.5 \pm 8.5$ \\
\hline $0.5 \mathrm{MCC}+\mathrm{P}+\mathrm{SP}+\mathrm{MS}$ & $30.5 \pm 0.6$ & 103.3 & $0.007 \pm 0.0004$ & $368.1 \pm 11.2$ \\
\hline $0.75 \mathrm{MCC}+\mathrm{P}+\mathrm{SP}+\mathrm{MS}$ & $26.7 \pm 0.6$ & 78.0 & $0.007 \pm 0.0005$ & $417.0 \pm 5.1$ \\
\hline
\end{tabular}

a MCC: micro crystalline cellulose, CMC: carboxymethyl cellulose, SP: superplasticizer, T: temperature, W: water: cement ratio, P: pluronic, MS: mechanical stirring.

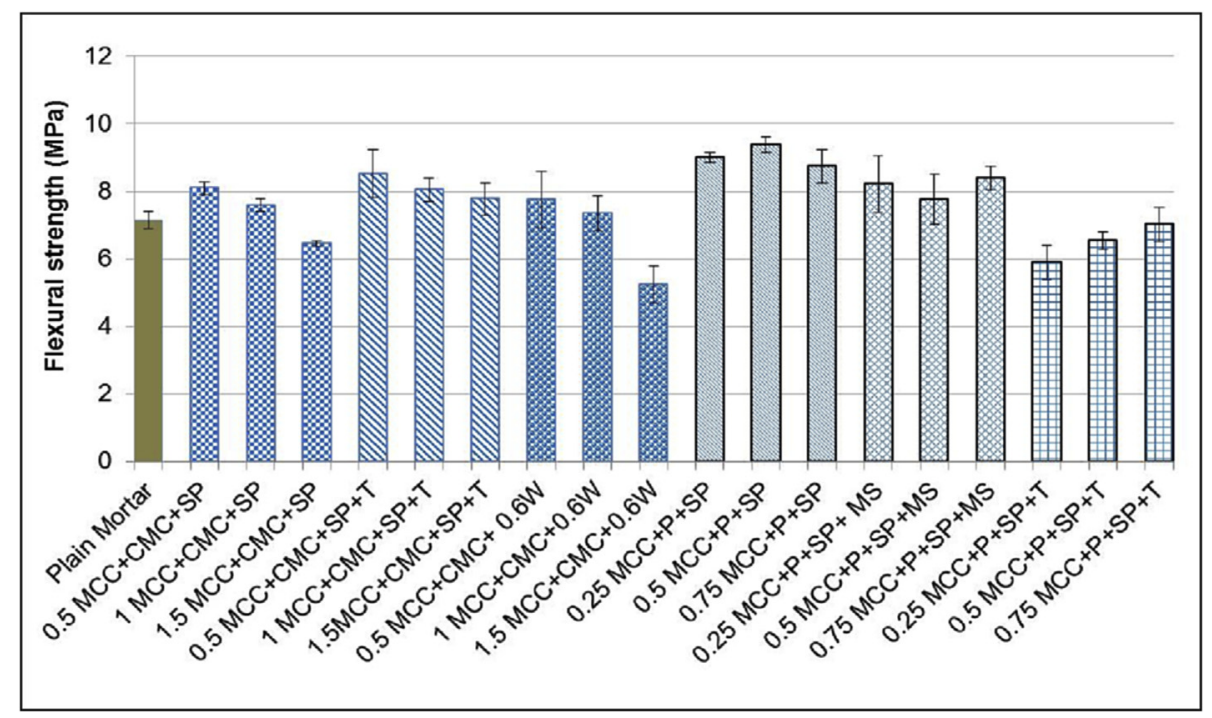

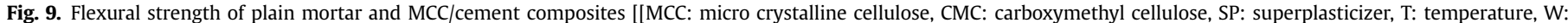
water: cement ratio, P: pluronic, MS: mechanical stirring].

composites. However, the presence of $\mathrm{Ca}$ and $\mathrm{Si}$ in the spectra of MCC present in the composites indicates that the cellulose crystals were coated with the cement hydration products. This was attributed to the growth of cement hydration products on the surface of cellulose crystals. The water retained by MCC was released and used in the hydration process of cement. Also, formation of hydrogen bonds between the hydroxyl groups of MCC and cement hydration products could also led to strong bonding between them. The strong interfacial bonding resulted in very good load transfer between MCC and cement matrix leading to considerable improvement in mechanical performance.

The addition of MCC significantly influenced the porosity of cementitious composites. The results of MIP analysis of plain mortar and MCC reinforced cementitious composites prepared using Pluronic are summarized in Table 9 and presented in Fig. 14. It can be observed from Table 9 that the porosity of cementitious composites increased slightly through addition of MCC, probably due to presence of MCC agglomerates. However, the average pore diameter decreased due to addition of MCC. Further, it is clear from Fig. 14 that majority of pores in case of plain mortar had a diameter of $\sim 95 \mathrm{~nm}$, which was reduced to $\sim 50 \mathrm{~nm}$ for MCC/mortar samples. However, the MCC/mortar samples contained more number of larger pores (as compared to plain mortar), although they were present in much lower amount. The reduction of pore size in case of MCC reinforced cementitious composites could be due to better hydration and might have contributed to the better mechanical properties of MCC reinforced cementitious composites.

In Table 10, the main findings of the present work have been compared with the previous studies on nano cellulose and MCC reinforced cementitious composites and also with the previous study on CNT reinforced cementitious composites prepared using Pluronic. It can be noticed that till now for fabricating nano cellulose and MCC reinforced cementitious composites no dispersion technique was used. As a result, CNC could be incorporated within 


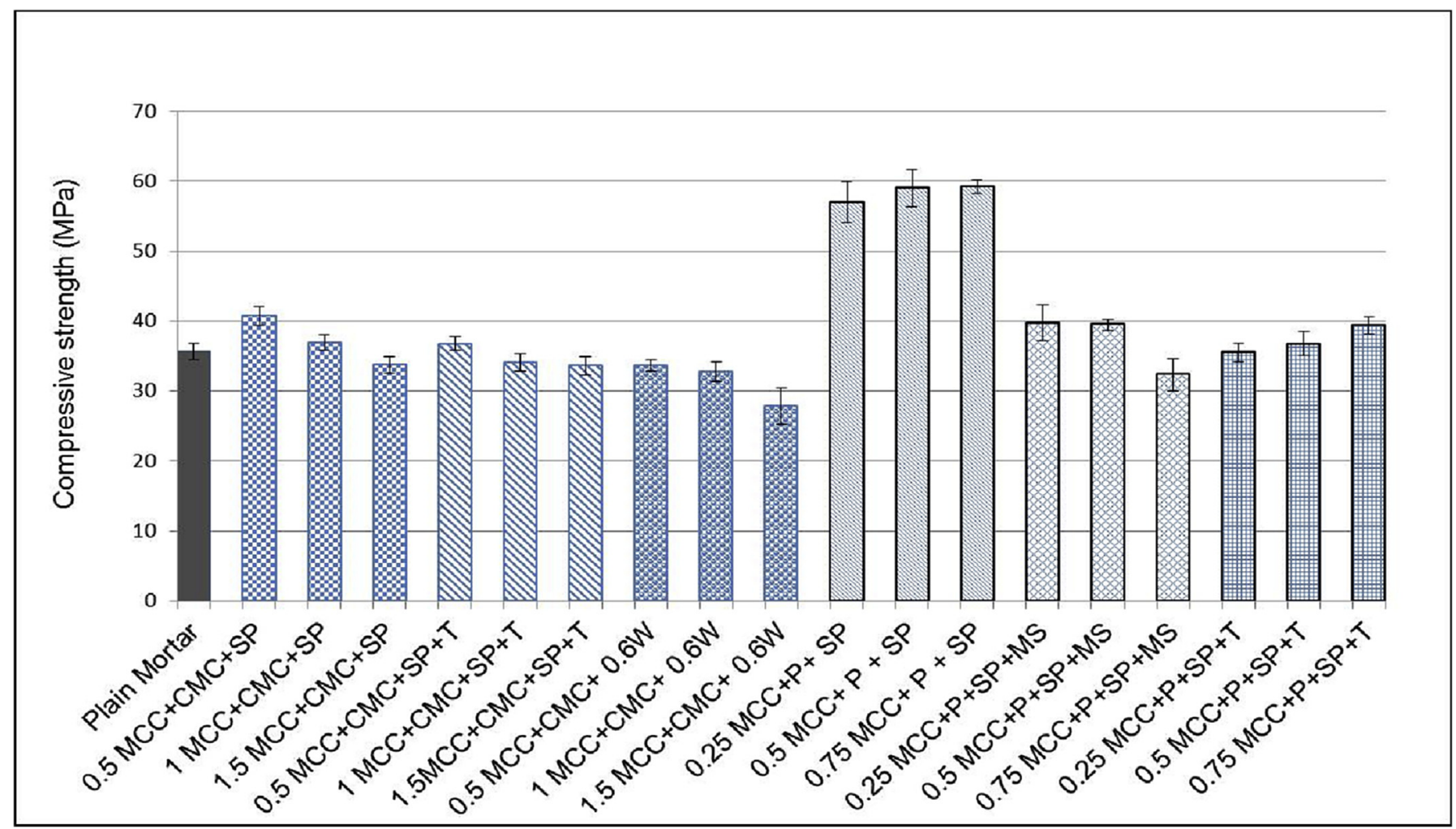

Fig. 10. Compressive strength of plain mortar and MCC/cement composites [MCC: micro crystalline cellulose, CMC: carboxymethyl cellulose, SP: superplasticizer, T: temperature, W: water: cement ratio, P: pluronic, MS: mechanical stirring].

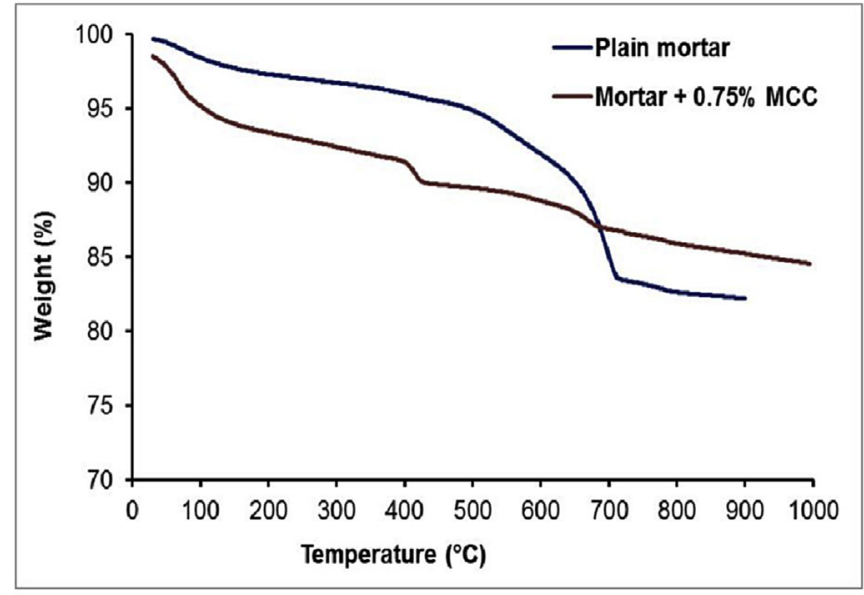

(a)

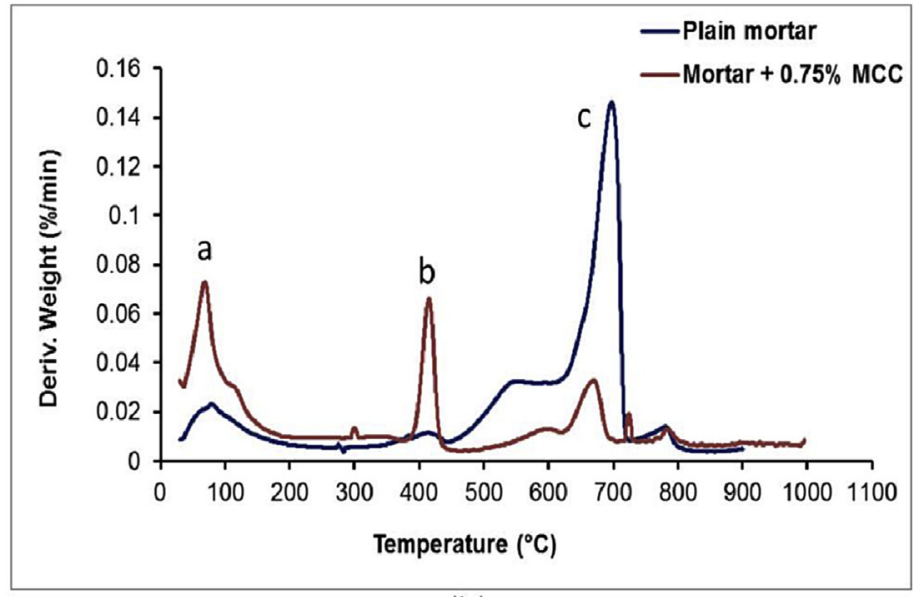

(b)

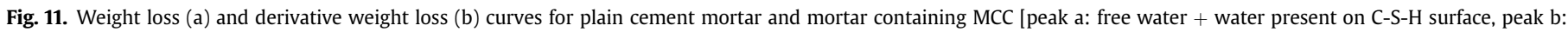
$\mathrm{Ca}(\mathrm{OH})_{2}$ decomposition, peak c: $\mathrm{CaCO}_{3}$ ].

cement composites without much agglomeration only up to 0.2 vol.\%, leading to a maximum increase in flexural strength by $30 \%$ [15]. On the other hand, incorporation of MCC up to $3 \mathrm{wt} \%$ could not improve mechanical properties of cementitious composites probably due to MCC agglomeration [17]. In the present study, homogeneous dispersion of MCC up to only $0.5 \mathrm{wt} \%$, achieved with ultrasonication process in presence of Pluronic, along with improved bulk density and microstructure obtained with superplasticizer combination resulted in 106\% improvement in flexural modulus, 31\% improvement in flexural strength and 66\% improvement in compressive strength. The improvement in mechanical properties was even higher as compared to $0.1 \mathrm{wt} \%$ SWCNT reinforced cementitious composites fabricated using the same dispersion technique, i.e. ultrasonication in presence of Pluronic [24]. However, a strong improvement in fracture energy was also obtained with SWCNT due to high extensibility of SWCNT 


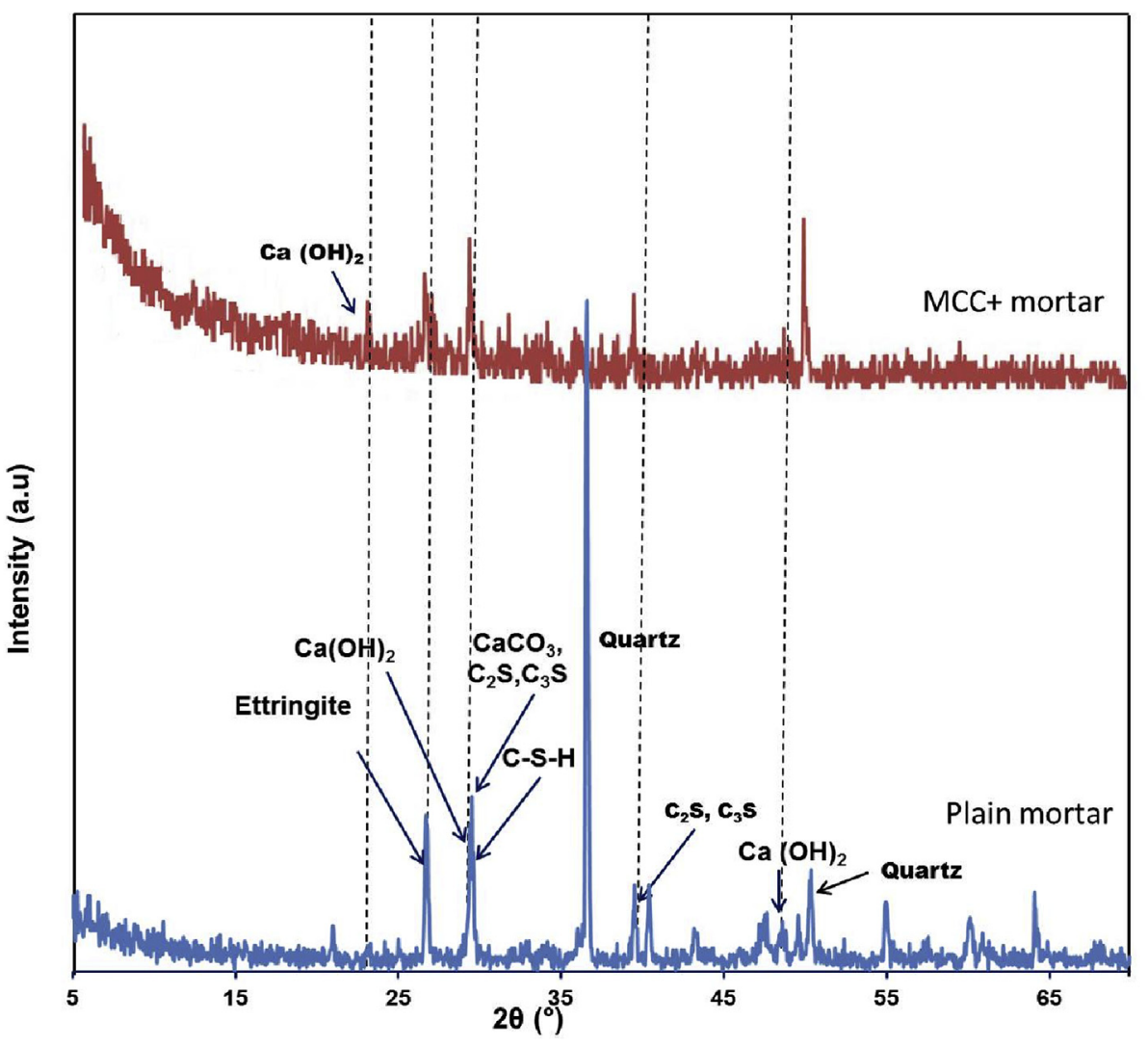

Fig. 12. XRD pattern of plain mortar and MCC reinforced cementitious composites.

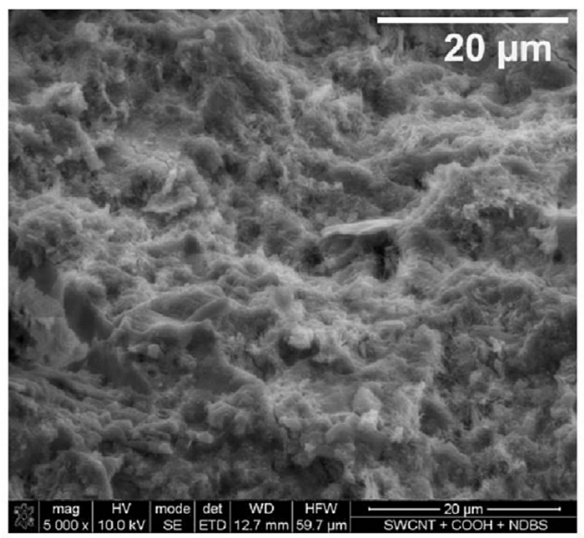

(a)

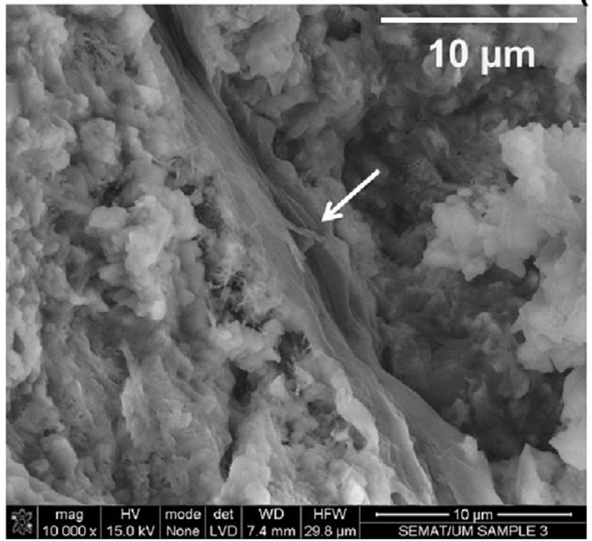

(b)

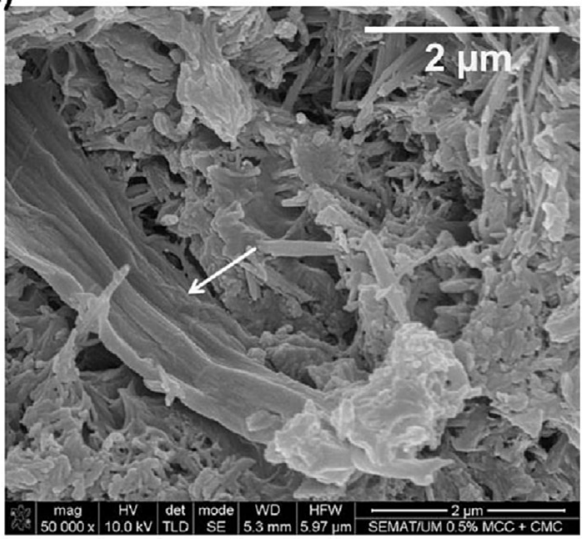

(c)

Fig. 13. Microstructure of plain mortar (a) and MCC reinforced cementitious composites at different magnifications (b and c). 
Table 8

Elements present in plain mortar and $\mathrm{MCC} /$ mortar samples.

\begin{tabular}{lllllllll}
\hline \multirow{2}{*}{ Samples } & \multicolumn{9}{l}{ Elements (Wt\%) } & & & & & \\
\cline { 2 - 9 } & $\mathrm{C}$ & 0 & $\mathrm{Na}$ & $\mathrm{Mg}$ & $\mathrm{Al}$ & $\mathrm{Si}$ & $\mathrm{S}$ & $\mathrm{Ca}$ \\
\hline Plain mortar & 11.44 & 45.59 & 0.29 & 0.31 & 0.77 & 3.93 & 0.61 & 36.25 \\
Plain mortar with MCC & 32.08 & 44.50 & - & 0.27 & 0.52 & 2.21 & 0.30 & 20.13 \\
\hline
\end{tabular}

Table 9

Pore diameter and porosity of plain mortar and $\mathrm{MCC} /$ mortar samples determined using MIP analysis.

\begin{tabular}{lll}
\hline Samples & Average Pore Diameter & Porosity \\
\hline Plain Cement Mortar & $47.4 \mathrm{~nm}$ & $10.5 \%$ \\
0.75\% MCC + Pluronic F-127 & $39.8 \mathrm{~nm}$ & $13.3 \%$ \\
\hline
\end{tabular}

along with high strength and stiffness. On the contrary, a decrease in fracture energy was observed in case of MCC reinforced cementitious composites developed in this research. Therefore, addition of a small amount of SWCNT to the MCC reinforced cementitious composites could be a feasible approach to solve this problem and achieve improved fracture energy along with excellent mechanical strength and stiffness.

\section{Conclusions}

In this work, MCC was dispersed in water using Pluronic F-127 and $\mathrm{CMC}$ and cementitious composites were fabricated using these suspensions. The influence of Pluronic/CMC concentration, superplaticizer, dispersion technique and temperature on the mechanical performance of cementitious composites was thoroughly studied. Major conclusions of this work are as follows:

- MCC can be well dispersed using Pluronic up to $0.6 \%$ using Pluronic: MCC ratio of 1:5. Using this ratio, no sedimentation of MCC was noticed and MCC was dispersed homogeneously without agglomeration. Above $0.6 \%$ MCC concentration, significant agglomeration occurred leading to sedimentation and considerable decrease in MCC concentration in solution.

- Overall, the dispersion quality of MCC using CMC (at CMC: MCC ratio of $1: 5)$ was inferior to Pluronic. For $0.4 \%-0.6 \% \mathrm{MCC}$, the conc. of MCC in suspension was similar and lower as compared to Pluronic. However, at higher conc., i.e. $1.5 \%$, the conc. of dispersed MCC was higher with CMC indicating that the use of CMC may be preferable for higher MCC concentrations.

- The bulk density of cement mortar increased significantly due to addition of Pluronic, CMC and MCC dispersed using Pluronic. This was attributed to the better dispersion of cement particles through steric stabilization mechanism.

- The addition of MCC to cementitious composites led to strong improvement in elastic modulus. The maximum improvement in flexural modulus was $106 \%$. The addition of MCC, however, reduced the breaking strain and fracture energy of cementitious matrix.

- Flexural and compressive strengths were highly dependent on various parameters. Higher mechanical properties were obtained with Pluronic due to better MCC dispersion as compared to CMC. The highest mechanical performance was achieved with Pluronic in combination with ultrasonication and

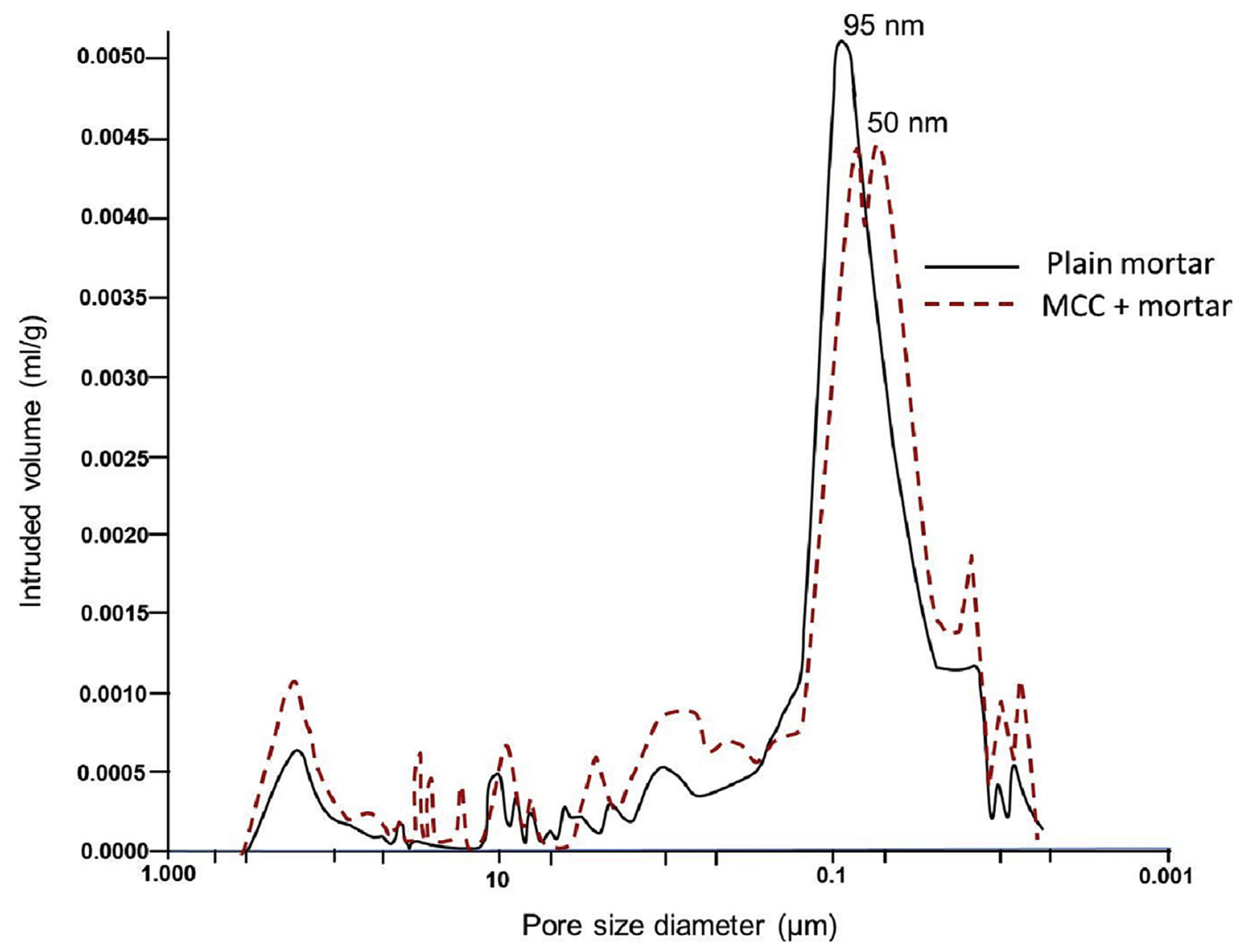

Fig. 14. Incremental intrusion volume of mercury versus pore diameter. 
Table 10

Comparison of main findings of present study with the previous studies on nano cellulose, MCC and CNT reinforced cementitious composites.

\begin{tabular}{|c|c|c|c|}
\hline $\begin{array}{l}\text { Type of } \\
\text { reinforcement }\end{array}$ & Dispersion technique & Main results & Reference \\
\hline $\begin{array}{l}\text { Cellulose nano } \\
\text { crystals (CNC) }\end{array}$ & $\begin{array}{l}\text { No. } \\
\text { As received CNC suspension } \\
\text { was directly mixed with cement }\end{array}$ & $\begin{array}{l}\text { Flexural strength improved by } 30 \% \text { through addition of } \\
0.2 \text { vol.\% CNC. At higher CNC loading, flexural strength } \\
\text { decreased due to agglomeration. Degree of cement } \\
\text { hydration increased with CNC addition }\end{array}$ & [15] \\
\hline $\begin{array}{l}\text { Micro crystalline } \\
\text { Cellulose (MCC) }\end{array}$ & $\begin{array}{l}\text { No. } \\
\text { Saturated MCC suspension was } \\
\text { directly added to cement mixture }\end{array}$ & $\begin{array}{l}\text { Addition of MCC to cement paste led to reduction of } \\
\text { mechanical properties in case of standard curing process. } \\
\text { Using accelerated curing, mechanical properties of } 0.3 \mathrm{wt} \% \\
\text { MCC added cement mortar reached close to the mechanical } \\
\text { properties of plain mortar. Hydration degree of cement } \\
\text { improved with MCC addition }\end{array}$ & [17] \\
\hline MCC & $\begin{array}{l}\text { Ultrasonication in presence of } \\
\text { Pluronic F-127 for } 15 \text { min. } \\
\text { Superplasticizer was used during } \\
\text { fabrication of cementitious composites }\end{array}$ & $\begin{array}{l}\text { Flexural modulus, flexural strength and compressive strength } \\
\text { improved by } 106 \%, 31 \% \text { and } 66 \% \text {, respectively. Hydration of } \\
\text { cement improved due to MCC addition }\end{array}$ & Present study \\
\hline $\begin{array}{l}\text { Single walled CNT } \\
\quad(\text { SWCNT })\end{array}$ & $\begin{array}{l}\text { Ultrasonication in presence of } \\
\text { Pluronic F-127 for } 1 \mathrm{~h}\end{array}$ & $\begin{array}{l}\text { Flexural modulus improved up to } 72 \% \text { with } 0.1 \% \text { SWCNT. } \\
\text { Flexural and compressive strengths improved up to } 7 \% \text { and } \\
19 \% \text { after } 28 \text { days of hydration and } 17 \% \text { and } 23 \% \text { after } 56 \text { days } \\
\text { of hydration. Fracture energy improved up to } 122 \%\end{array}$ & [24] \\
\hline
\end{tabular}

superplasticizer. Maximum improvements in flexural and compressive strengths were $31 \%$ and $66 \%$, respectively obtained through addition of $0.5 \%$ MCC using Pluronic.

- When added to cement matrix, MCC could be well wetted by the matrix leading to strong interface between MCC and cement hydration products. The addition of MCC led to better hydration and reduction in pore size of cementitious matrix.

The present study, therefore, shows the possibility of developing high performance cementitious composites through homogeneous dispersion of MCC using Pluronic F-127 and the findings will, therefore, be highly useful for construction applications.

\section{Acknowledgements}

The authors acknowledge the Portuguese Fundação para a Ciência e a Technologia (FCT) for financial support through project PEst-C/CTM/LA0025/2013 (Strategic Project - LA 25 - 2013-2014). The authors also acknowledge the financial support from Portuguese National Funding, through, on the framework of project UID/ CTM/00264/2013 and national funds through FCT, I.P., within the research unit C-MADE, Centre of Materials and Building Technologies (CIVE-Centro-Covilhã-4082), Universidade da Beira Interior, Portugal.

\section{Supplementary material}

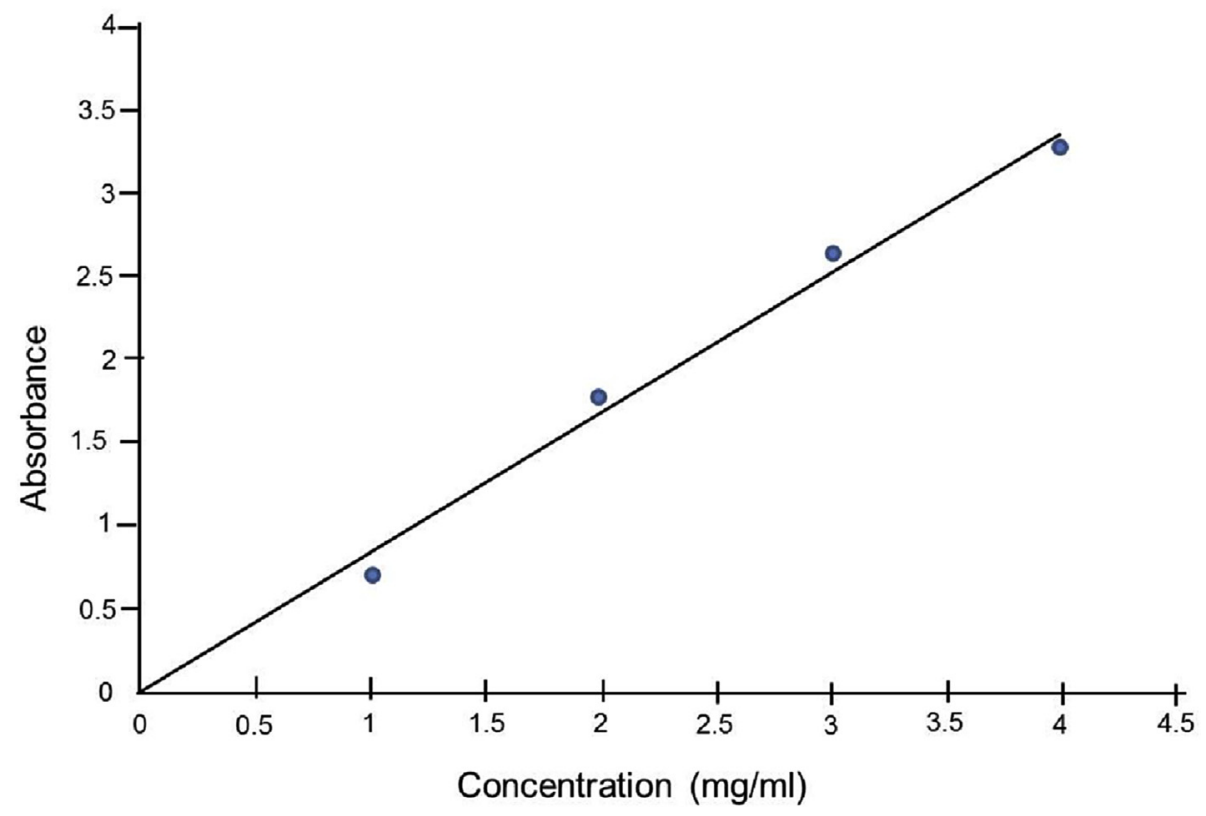

Fig. 1S. Calibration curve for measuring MCC concentration in aqueous suspensions. 


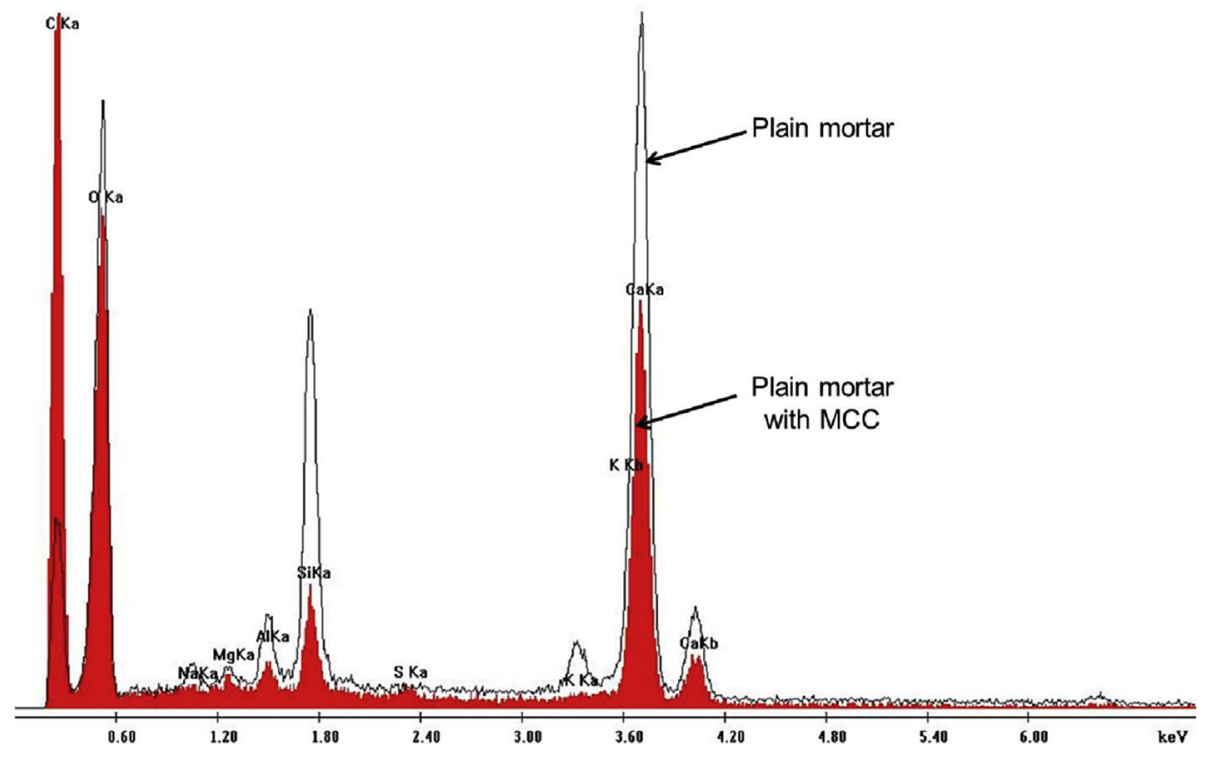

Fig. 2S. EDS spectra of plain mortar and MCC/cement composites.

\section{References}

[1] Shama Parveen, Sohel Rana, Raul Fangueiro, Maria Conceição Paiva, Microstructure and mechanical properties of carbon nanotube reinforced cementitious composites developed using a novel dispersion technique, Cem. Concr. Res. 73 (2015) 215-227.

[2] Y. Akkaya, S.P. Shah, M. Ghandehari, Influence of fiber dispersion on the performance of microfiber reinforced cement composites, Am. Concr. Inst. Sp. 216 (2003) $1-18$.

[3] Y. Qing, Z. Zenan, K. Deyu, Influence of nano- $\mathrm{SiO}_{2}$ addition on properties of hardened cement paste as compared with silica fume, Constr. Build. Mater 21 (3) (2007) 539-545.

[4] B.Y. Lee, K.E. Kurtis, Influence of TiO2 nanoparticles on early C3S hydration, J. Am. Ceram. Soc. 93 (10) (2010) 3399-3405.

[5] Zoi S. Metaxa, Maria S. Konsta-Gdoutos, Surendra P. Shah, Carbon nanofiber cementitious composites: effect of debulking procedure on dispersion and reinforcing efficiency, Cem. Concr. Compos. 36 (2013) 25-32.

[6] Maria S. Konsta-Gdoutos, Chrysoula A. Aza, Self sensing carbon nanotube (CNT) and nanofiber (CNF) cementitious composites for real time damage assessment in smart structures, Cem. Concr. Compos. 53 (2014) 162-169.

[7] A., Dufresne, Nanocellulose: a new ageless bionanomaterial, Mater. Today 16 (6) $220-227$.

[8] B.L. Peng, N. Dhar, H.L. Liu, K.C. Tam, Chemistry and applications of nanocrystalline cellulose and its derivatives: a nanotechnology perspective, Can. J. Chem. Eng. 89 (5) (2011) 1191-1206.

[9] Serge Rebouillat, Fernand Pla, State of the art manufacturing and engineering of nanocellulose: a review of available data and industrial applications, J. Biomater. Nanobiotechnol. 4 (2) (2013) 165.

[10] Stephen J. Eichhorn, A. Dufresne, M. Aranguren, N.E. Marcovich, J.R. Capadona, S.J. Rowan, Christoph Weder, et al., Review: current international research into cellulose nanofibres and nanocomposites, J. Mater. Sci. 45 (1) (2010) $1-33$.

[11] M.A. Hubbe, O.J. Rojas, L.A. Lucia, M. Sain, Cellulosic nanocomposites: a review, BioResources 3 (3) (2008) 929-980.

[12] S. Spoljaric, A. Genovese, R.A. Shanks, Polypropylene-microcrystalline cellulose composites with enhanced compatibility and properties, Compos. Part A Appl. Sci. Manuf. 40 (6) (2009) 791-799.

[13] MK Mohamad Haafiz, Azman Hassan, Zainoha Zakaria, Ibrahim Mohammed Inuwa, Md Sakinul Islam, Mohammad Jawaid, Properties of polylactic acid composites reinforced with oil palm biomass microcrystalline cellulose, Carbohydr. Polym. 98 (1) (2013) 139-145.

[14] Alper Kiziltas, Douglas J. Gardner, Yousoo Han, Han-Seung Yang, Mechanical properties of microcrystalline cellulose (MCC) filled engineering thermoplastic composites, J. Polym. Environ. 22 (3) (2014) 365-372.
[15] Y. Cao, P. Zavaterri, J. Youngblood, R. Moon, J. Weiss, The influence of cellulose nanocrystal additions on the performance of cement paste, Cem. Concr. Compos. 56 (2015) 73-83.

[16] Faranak Mohammadkazemi, Kazem Doosthoseini, Eshmaiel Ganjian, Mehrdad Azin, Manufacturing of bacterial nano-cellulose reinforced fibercement composites, Constr. Build. Mater. 101 (2015) 958-964.

[17] C.G. Hoyos, E. Cristia, A. Vázquez, Effect of cellulose microcrystalline particles on properties of cement based composites, Mater. Des. 51 (2013) 810-818.

[18] Adam J. Blanch, Claire E. Lenehan, Jamie S. Quinton, Optimizing surfactant concentrations for dispersion of single-walled carbon nanotubes in aqueous solution, J. Phys. Chem. B 114.30 (2010) 9805-9811.

[19] Sohel Rana, Ramasamy Alagirusamy, Mangala Joshi, Development of carbon nanofibre incorporated three phase carbon/epoxy composites with enhanced mechanical, electrical and thermal properties, Compos. Part A Appl. Sci. Manuf. 42 (5) (2011) 439-445.

[20] J. Luo, Z. Duan, H. Li, The influence of surfactants on the processing of multiwalled carbon nanotubes in reinforced cement matrix composites, Phys. Status Solidi A 206 (12) (2009) 2783-2790.

[21] A. Cwirzen, K. Habermehl-Cwirzen, V. Penttala, Surface decoration of carbon nanotubes and mechanical properties of cement/carbon nanotube composites, Adv. Cem. Res. 20 (2) (2008) 65-73.

[22] Gianni Ciofani, et al., Dispersion of multi-walled carbon nanotubes in aqueous pluronic F127 solutions for biological applications, Fullerenes, Nanotub. Carbon Nanostruct. 17.1 (2009) 11-25.

[23] N.R. Arutyunyan, D.V. Baklashev, E.D. Obraztsova, Suspensions of single-wall carbon nanotubes stabilized by pluronic for biomedical applications, Eur. Phys. J. B-Condensed Matter Complex Syst. 75.2 (2010) 163-166.

[24] Shama Parveen, Sohel Rana, Raul Fangueiro, Maria Conceição Paiva, Microstructure and mechanical properties of carbon nanotube reinforced cementitious composites developed using a novel dispersion technique, Cem. Concr. Res. 73 (2015) 215-227.

[25] http://www.hawkinswatts.com/documents/ DispersionofcolloidalgradesofAvicel.pdf. (accessed 15.02.16).

[26] C.L.S. Lau, Q. Yu, V.Y. Lister, S.L. Rough, D.I. Wilson, M. Zhang, The evolution of pellet size and shape during spheronisation of an extruded microcrystalline cellulose paste, Chem. Eng. Res. Des. 92 (11) (2014) 2413-2424.

[27] MK Mohamad Haafiz, Azman Hassan, Zainoha Zakaria, Ibrahim Mohammed Inuwa, Md Sakinul Islam, Mohammad Jawaid, Properties of polylactic acid composites reinforced with oil palm biomass microcrystalline cellulose, Carbohydr. Polym. 98 (1) (2013) 139-145.

[28] Foteini Kontoleontos, Petros Tsakiridis, Apostolos Marinos, Nikolaos Katsiotis, Vasileios Kaloidas, Margarita Katsioti, Dry-grinded ultrafine cements hydration. physicochemical and microstructural characterization, Mater. Res. 16 (2) (2013) 404-416. 